\title{
Incorporating temperature and precipitation extremes into process-based models of African lepidoptera changes the predicted distribution under climate change
}

\author{
Madeleine G. Barton ${ }^{\mathrm{a}, 1}$, John S. Terblanche ${ }^{\mathrm{a}}$, Brent J. Sinclair ${ }^{\mathrm{b}, *}$ \\ ${ }^{a}$ Department of Conservation Ecology and Entomology, Centre for Invasion Biology, Stellenbosch University, Private Bag XI, Western Cape, South Africa \\ ${ }^{\mathrm{b}}$ Department of Biology, University of Western Ontario, London, ON, Canada
}

\section{A R T I C L E I N F O}

\section{Keywords:}

Mechanistic model

Climate change

Thermal physiology

Dehydration

Butterfly

Moth

Pest management

\begin{abstract}
A B S T R A C T
Terrestrial insects are responding to ongoing climate change. While these responses have been primarily linked to rising temperatures, insects are sensitive to desiccation, and the impacts of altered precipitation regimes remain relatively unexplored. Here, we develop a mechanistic model of survival and performance responses to both temperature and desiccation stress, focussing on Lepidoptera in Africa, where a general understanding of such responses to climate change is urgently required. We run the model with climate data from general circulation models at daily time intervals under current (2011-2015) and projected future (2046-2050) climate scenarios. We first simulate four hypothetical, but typical, Lepidoptera that vary in thermal tolerance and developmental physiology, and then add a constraint on survival due to desiccation. Including desiccation stress leads to a $68 \%$ decline in the species range, in comparison to simulations where only species mortality due to temperature is considered. Furthermore, in response to predicted changes in both temperature and rainfall, species performances and survival are expected to change in a non-uniform manner across the landscape: species' ranges shift towards coastal regions and into higher latitudes in the southern, but not northern, hemisphere. We validate the model predictions with data from two endemic African Lepidoptera, and find that the model agrees well with their empirical distribution, but note that our model fails to account for range expansion due to water availability unrelated to rainfall (e.g. irrigation). Nonetheless, these final simulations show how the model can be readily applied to insects for which baseline physiological data already exist (or for which appropriate data can be gathered), thereby providing a useful framework with which to explore species responses to future changes in temperature and precipitation.
\end{abstract}

\section{Introduction}

Climate change is having pronounced global effects on the geographic distribution, phenology, and performances of insects and other ectotherms. Many of these responses are directly linked to increased temperatures over the past century, resulting in poleward or upward distribution shifts (Chen et al., 2011; Parmesan et al., 1999). However, temperature is just one of the environmental determinants of species distribution and performance: the integrative effects of multiple environmental components are poorly understood and rarely incorporated into species distribution models (Todgham and Stillman, 2013, but see Kearney and Porter, 2009). As vectors for disease, agricultural pests and providers of important ecosystem services (e.g. pollination), accurately predicting insect responses to climate change is a high priority (Bebber et al., 2013). The performance and distribution of terrestrial insects is sensitive to both water availability and temperature (Harrison et al., 2012). However, the effects of low water availability on a species' performance and survival (Kleynhans and Terblanche, 2011) are usually ignored in favour of temperature-based assessments (e.g. Deutsch et al., 2008). One way to address these complexities is to use a modelling approach that allows us to explicitly consider several different stressors and the life-stage-specific responses to these stressors, at high spatial and temporal resolutions.

Correlative species distribution models (SDMs) are used to predict the impacts of climate change on the future distributions of organisms (Elith and Leathwick, 2009). These models typically use long-term ( $30+$ years) average climatic records on monthly, quarterly, or annual time scales to determine a species' 'current' requirements, and then

\footnotetext{
* Corresponding author.

E-mail address: bsincla7@uwo.ca (B.J. Sinclair).

${ }^{1}$ Present address: CSIRO, Black Mountain, ACT 2601, Australia.
} 
predict the distribution of that envelope of requirements in the future. While a species' requirements are probably correlated with such average climatic patterns, these patterns often do not reflect the organism's experience in nature, and these models necessarily assume that relationships between these averages and the actual microclimate experienced, the occurrence of extreme events, and correlations in the sequence and intensity of stress exposure will remain similar in the future (Colinet et al., 2015; Coumou and Rahmstorf, 2012; Dowd et al., 2015; Gaines and Denny, 1993; Kaunisto et al., 2016; Potter et al., 2013). It is therefore not surprising that SDMs that incorporate fine temporal resolution outperform those built with longer-term climatic averages (Reside et al., 2010; Sheldon and Dillon, 2016).

Process-based (also 'mechanistic' or 'bottom-up') modelling approaches provide an alternative to correlative approaches that can incorporate more subtle interactions between an organism and its environment (Buckley et al., 2010; Maino et al., 2016). These models generally comprise a framework that reflects the different ways in which a species might interact with its environment (Buckley et al., 2010; Maino et al., 2016; Sears et al., 2011). For example, Bonebrake et al., (2014) used biophysical models combined with high-resolution climate records and life-history datasets of a widespread American butterfly (Chlosyne lacinia) to show that population fitness under future climate scenarios depends, in part, on the behavioural thermoregulation of the butterfly. These responses can be tracked through multiple time-steps to account for responses to abiotic conditions (Maino et al., 2016), variation among life-history stages (Kingsolver et al., 2011), and, we propose, characterise responses to multiple environmental stressors.

Explicitly defining climate-organism interactions in a model can afford greater confidence in its predictions when applied to novel climates (Kearney and Porter, 2009), however a commonly-cited limitation of the process-based modelling approach is the large amount of species-specific information that is required (Morin and Thuiller, 2009). Data can indeed be hard to come by for many species. However, due to their overall diversity, and their status as agricultural pests and vectors of disease, some useable datasets already exist for terrestrial insects (Harcourt, 1969; Mironidis, 2014). For example, degree-day models have traditionally been used by agronomers to predict the emergence of key insect pests, and there is a wealth of species information associated with this technique. These datasets allow us to use realistic biological variation to make some generalities about life cycle and physiology for dominant pest taxa for developing working process-based models at a range of temporal and spatial scales.

As small ectotherms, terrestrial insects are particularly sensitive to variation in both temperature and water availability, and among species these sensitivities can vary both across the landscape and through time (Kingsolver et al., 2011; Sinclair et al., 2012; Potter et al., 2013). Insect responses to extreme conditions are duration-dependent: brief exposure to temperatures beyond the critical thermal limits can lead to mortality in minutes to hours (Sinclair et al., 2016; Terblanche et al., 2011), while at the same time exposure to sub-lethal environmental stress can accumulate over timeframes from hours to weeks and months, and even across life stages and generations (Buckley and Huey, 2016; Crill et al., 1996; Ma et al., 2015; Zhou et al., 2013). For example, in the laboratory the tsetse fly (Glossina pallidipes) has a $C T_{\max }$ of $44^{\circ} \mathrm{C}$ if temperatures are quickly ramped up from benign conditions $\left(35^{\circ} \mathrm{C}\right)$ at a rate of $0.25^{\circ} \mathrm{C}$ per minute, but at an ecologically-realistic ramping rate of $0.06{ }^{\circ} \mathrm{C}$ per minute, mortality occurs at $40^{\circ} \mathrm{C}$ (Terblanche et al., 2007). At a landscape scale, the effects of both temperature and precipitation are difficult to capture with (correlative) SDM frameworks as these two parameters generally co-vary across the landscape. In addition, the temporal component of these stressors cannot be captured in models that use aggregated measures of these parameters, such as rainfall of the wettest and/or driest quarters (Busby, 1991; Elith et al., 2006; Helmuth et al., 2014; Hijmans et al., 2005; Kumar et al., 2015; de la Vega and Schilman, 2017). For insects that reside in irrigated habitats or have access to permanent water bodies, water availability is decoupled from precipitation, so the effects of thermal and desiccation stress, and any associated adaptations that arise from these stressors, may make understanding their responses to climate change (even) more difficult to interpret (de Villiers et al., 2016, 2017).

Here we develop a process-based model that incorporates information on an insect's sensitivity to temperature and water availability with spatially explicit climatic datasets to predict how the species' performance and survival might vary across Africa. We focus on Africa, because insects have important implications for human populations; as agricultural pests, disease vectors, and as providers of ecosystem services in a region where the primary diseases are vectored by insects and food security is becoming increasingly tenuous (Battisti and Naylor, 2009; Caminade et al., 2013; Knox et al., 2012; Serdeczny et al., 2016; Wheeler and von Braun, 2013). Despite these concerns, ecological studies with broad relevance to insects in Africa are sparse relative to those undertaken in North America, Europe and Asia, and a baseline understanding of how pests on the continent are responding to changes in climate is urgently required (Biber-Freudenberger et al., 2016; Müller et al., 2011).

Moreover, the continent encompasses many different biomes from deserts to the wet tropics, ranging from low to high elevations. As such, Africa provides a diverse climate mosaic across which to test how, in general, variation in an insect's sensitivity to thermal and desiccation stress might influence its distribution and performance in different habitats, and whether a process-based model can adequately account for - or at least explain a significant proportion of - this diversity.

We begin by developing our model with hypothetical holometabolous insects (nominally Lepidoptera, which are important crop pests across Africa) that differ in developmental physiology and thermal tolerance, and then add a constraint on survival due to lack of water availability during periods of low rainfall. We use fine-scale daily estimates of temperature and rainfall spanning a five-year period for current (2011-2015), and future conditions (2046-2050) based on a General Circulation Model (GCM) scenario that reflects current trajectories of greenhouse gas emissions (IPCC, 2014). We use these hypothetical insects to explore i) the role of temperature- and desiccationresistance in determining the overall occupancies and population performances of holometabolous pest insects in Africa; ii) the extent to which predicted changes in these environmental parameters will affect the occupancy and population performances of holometabolous insects in Africa; and then, iii) we validate our model against published datasets describing the thermal tolerances and developmental physiologies of two endemic African Lepidoptera: an agricultural pest (Busseola fusca) and a well-studied butterfly (Bicyclus anynana). We find that models incorporating desiccation responses provide much more realistic predictions of insect distribution across Africa than those based on temperature alone. While the model provides a useful framework for exploring interactive effects of multiple concurrent stressors on a species, as well as how species adaptations to selective pressures might shape its future distribution and performance, these questions are beyond the scope of the current study. Nonetheless, our simulations show that temperature and water constrain species survival in different ways, and that - depending on the species' physiological tolerances - distributions and population performances under climate change will vary in a non-uniform manner across the continent.

\section{Methods}

\subsection{Model input data}

\subsubsection{Insect physiology data}

To compare how distributions of species with different life-histories and thermal tolerances vary across the landscape, we generated datasets for four hypothetical, but spanning a realistic range, of holometabolous insects (Table 1). We created two fast-developing species (total 
Table 1

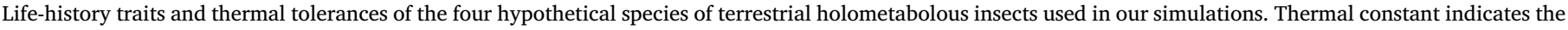

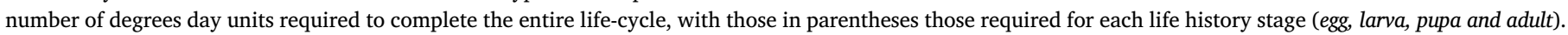
$C T_{\min }, C T_{\max }$, LDT and UDT are the critical thermal minimum and maximum and the lower and upper developmental temperature thresholds respectively.

\begin{tabular}{|c|c|c|c|c|c|c|c|}
\hline Species & Development Rate & Thermal Constant (K) & Thermal tolerance & $C T_{\min }$ & $C T_{\max }$ & LDT & UDT \\
\hline 1 & Fast & 600 & Broad & 2 & 45 & 8 & 40 \\
\hline 2 & Fast & $(50,300,150,100)$ & Narrow & 8 & 38 & 12 & 35 \\
\hline 3 & Slow & 1600 & Broad & 2 & 45 & 8 & 40 \\
\hline 4 & Slow & $(300,700,500,100)$ & Narrow & 8 & 38 & 12 & 35 \\
\hline
\end{tabular}

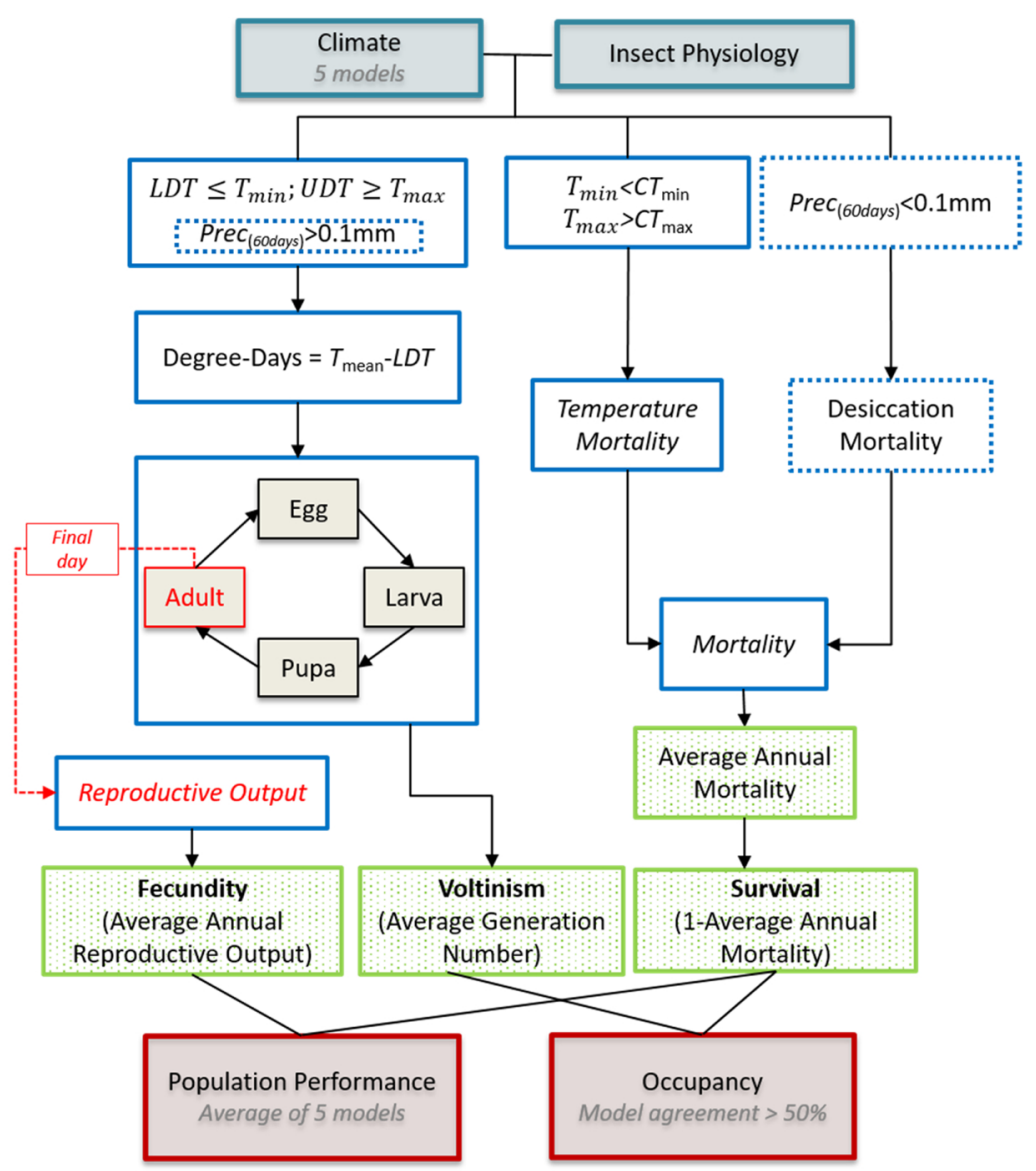

Fig. 1. Schematic of the model framework that incorporates climate (of the five CMIP5 model projections, see text for details) with insect physiological datasets (blue shaded boxes) to determine survival, development and fecundity. Blue boxes indicate calculations conducted on daily time-steps while green boxes represent parameters summarized over the full five-year simulation to attain an average annual measure. Fecundity measures (red) apply only to the adult stage. The model was driven initially with temperature constraints only, and then repeated with sensitivity to desiccation, boxes with dashed outline. Model outputs are indicated in red shaded boxes (For interpretation of the references to colour in this figure legend, the reader is referred to the web version of this article).

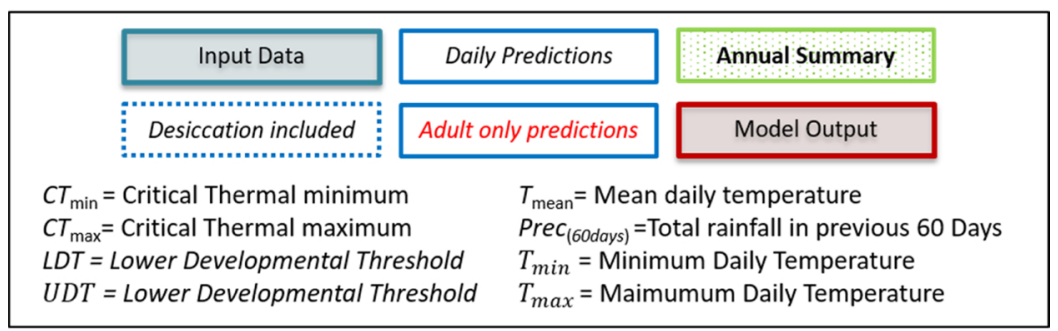

degree-day units required to complete a generation: $K=600$ ), and two slow-developing species $(K=1600)$. Here, $K$ represents the thermal constant, or the number of degree days required to complete development from a freshly laid egg to adult eclosion. This value is typically calculated from the inverse of the temperature-development rate relationship, assuming a linear relationship between temperature and development (Damos and Savopoulou-Soultani, 2012). Within each of these two life-histories one species had a broad, and the other a narrow thermal tolerance range (Table 1 ) that differed in their critical thermal maximum $\left(C T_{\max }\right)$, critical thermal minimum $\left(C T_{\min }\right)$, lower developmental threshold (LDT) and upper developmental thresholds (UDT). To assess how sensitivity to desiccation further affected these four species responses we set an additional constraint on performance due to low water availability, whereby the insect was stressed and mortality incurred if the cumulative precipitation for the previous 60 days was below $0.1 \mathrm{~mm}$ (i.e. a run of 60 consecutive "dry" days was encountered). This additional desiccation sensitivity was the same for all four species.

\subsubsection{Climate data}

Current and future climatic conditions predicted by the Coupled Model Intercomparison Project phase 5 (CMIP5, Riahi et al., 2011; Taylor 
et al., 2012), were sourced from the Earth System Grid (http://pcmdi9. llnl.gov/). More specifically, we downloaded daily predictions of precipitation, average surface temperature $\left(T_{\text {mean }}\right)$, minimum surface temperature $\left(T_{\min }\right)$, and maximum surface temperature $\left(T_{\max }\right)$. We considered two climate scenarios: the "historical" experiment for conditions spanning 2011 to 2015, as well as climates predicted for 2046 to 2050 under a radiative forcing of $8.5 \mathrm{~W} . \mathrm{m}^{-2}$ (Representative Concentration Pathway 8.5), the most extreme climate warming scenario included in the IPCC Fourth Assessment report (IPCC, 2007), but one that is representative of current trajectories (Jackson et al., 2017). The CMIP5 database includes several different modelling experiments reflecting variation among forcing experiments and institutions (Garcia et al., 2012; Tierney et al., 2015). To account for these discrepancies we ran five iterations of our model simulations each with a different set of input climatic data from outputs of five climate modelling experiments, for which daily predictions of the required climatic parameters were available (HadGEM2-ES, CNRM-CM5, MPI-ESM-LR, CMCC-CESM, IPSLCM5A-LR; Supplementary Material; Table A1). From these global datasets, we extracted data for Africa only. Because the spatial resolutions among these five climate models vary, to allow for comparisons among the different projections, each dataset was re-sampled at a resolution of approximately $1^{\circ}$ using bilinear interpolation with the Raster package in R (Hijmans and van Etten, 2012; Tierney et al., 2015; see Table A.1 for original resolutions). The simulations described below were run with each of these five climatic datasets and from these outputs, we 1) calculated average population performance in each grid cell and, 2) determined if the species could survive in each grid cell where at least three models ( $>50 \%$ model agreement) predicted occupancy (see methods below and Araujo and New, 2006).

\subsection{Model development}

We developed a process-based model that used these high temporalresolution datasets of temperature and precipitation through multiple years (Fig. 1). For each time-step, survival and population performance based on key life-history traits were determined by comparing the daily temperature and precipitation predictions against each hypothetical insect's thermal and desiccation tolerances and developmental rates. All modelling and statistical analyses were conducted in R Version 3.1.1 ( $R$ Core Team, 2014).

\subsubsection{Phenology}

The model commenced on the first of January as a freshly laid egg, making the assumption that adult females are present and gravid at each location across the landscape on this particular day. For every daily time-step thereafter, the model integrated predictions of the $T_{\text {mean }}$ (daily mean temperature) into a linear degree-day model such that

Degree. Day units $=\left\{\begin{array}{cl}T_{\text {mean }}-L D T, & L D T \leq T_{\min } ; U D T \geq T_{\max } ; D S=0 \\ 0, & L D T \geq T_{\min } ; U D T \leq T_{\max } ; D S=1\end{array}\right.$

where $T_{\min }$ and $T_{\max }$ are the minimum and maximum daily temperatures, and LDT and UDT are the lower and upper developmental thresholds, respectively. This assumes that the insect's body temperature closely reflects the $T_{\text {mean }}$ of each day. If the predicted daily $T_{\text {min }}$ and $T_{\max }$ fell below or rose above the animal's LDT and UDT respectively, and/or if desiccation stress ( $D S$ ) was encountered (see above), development during that particular day ceased and no additional degree-day units were accumulated (Fig. 1). As the model simulation progressed, development through the egg, larval and pupal stages was tracked based on a cumulative thermal constant $(\mathrm{K})$ that was required for each life-history stage (Fig. 1; Table 1). For our hypothetical species, we use typical values of $\mathrm{K}$ for holometabolous insects, that are determined by calculating the inverse of the slope of the temperature development rate curve (assuming a linear function (Nietschke et al.,
2007)). Upon eclosion the adult was set to persist for a period of 100 degree-day units on the assumption that high temperatures accelerate rates of aging (Miquel et al., 1976). At the end of the 100 degree-day period, the (female) adult laid a clutch of eggs, the number of which depended on the temperature of that particular day (Eq. (6), see below), and the model re-commenced development as a freshly laid egg (i.e. the number of accumulated degree day units was reset to zero). The model continued to step through the insect's life-cycle in this manner until the end of the five-year model simulation (1825 daily time-steps in total), upon which the total number of generations was averaged across the five years to yield an annual measure of voltinism (Fig. 1). This simulation was repeated for each grid-cell across the landscape.

\subsubsection{Performance}

As well as voltinism, we calculated a composite fitness index by combining predictions of fecundity and survival into a measure of population performance, where:

Population performance $=$ Survival $\times$ Fecundity

Here, we assumed that Survival is inversely proportional to the frequency and severity of lethal conditions, where temperature and water availability exceed the critical limits of the species. When such environmental stress was encountered, we set population abundance to decline according to the perceived severity of the stress. More specifically, at any given location, for every degree increment beyond the lifestage's $C T_{\min }$ and $C T_{\max }$, we assumed that a set proportion of the population could not persist, described by:

Temperature mortality $=\left\{\begin{array}{c}\left(T_{\max }-C T_{\max }\right) \times 40, T_{\max }>C T_{\max } \\ \left(C T_{\min }-T_{\min }\right) \times 10, T_{\min }<C T_{\min } \\ 0, T_{\max }<C T_{\max } ; \\ T_{\min }>C T_{\min }\end{array}\right.$

According to this definition, "extreme" temperature days had a $T_{\min }$ $10^{\circ} \mathrm{C}$ below or $T_{\max } 2.5^{\circ} \mathrm{C}$ above the insect's $C T_{\min }$ or $C T_{\max }$, respectively (Table 1 ), leading to $100 \%$ (temperature) mortality of the population. Here, in accordance with laboratory trials, we assume that mortality to temperatures above the $C T_{\max }$ is more pronounced than mortality to temperatures below the species' $C T_{\text {min }}$ (Mitchell et al., 2017; Terblanche et al., 2011, see discussion in Kingsolver and Umbanhowar, 2018). When daily $T_{\min }$ and $T_{\max }$ measures exceeded the $10^{\circ} \mathrm{C}$ and $2.5^{\circ} \mathrm{C}$ thresholds respectively, population mortality was capped at $100 \%$.

For simulations incorporating a desiccation constraint, if desiccation stress was encountered on a particular day, mortality rates due to this stress were determined by summing the total number of days within the previous 60 without rain. This value was incorporated into a typical exponential survival curve, such that:

Desiccation mortality $=\frac{0.2 \times e^{\left(\frac{\text { days without rain }}{9.65}\right)}}{100}$

Accordingly, $100 \%$ population (desiccation) mortality occurred on days when the 60 preceding days had no recorded precipitation.

On days when temperature and desiccation mortality occurred simultaneously, the proportion of deaths within the population was assumed to be that of the most stressful parameter, defined by the maximum value of equations three or four (i.e. deaths occurred due to either heat, cold, or desiccation stress in a non-additive manner). The model output thus included a daily measure of relative population mortality, be it through desiccation or temperature stress (Fig. 1).

At each location, these daily mortality values were subsequently summed throughout the five-year simulation period, and then averaged each year to generate an estimate of Average annual mortality. To generate an estimate of Survival we divided this by the maximum number of deaths that could potentially have occurred annually (potential population mortality due to 365 "extreme" weather days $=365 \times 100$ ) 
whereby:

Survival $=1-\left(\frac{\text { Average annual mortality }}{36,500}\right)$

Although there is the possibility of antagonistic or synergistic responses to interacting stressors (e.g. death from desiccation is more likely at higher temperatures; Sinclair et al., 2016) here we assume mortality due to one stressor occurs independently of the other. We also make the assumptions that: 1) the core-body temperatures of the insects are the same as the ambient surface temperature predictions and;2) no sources of water other than precipitation are available to the insect.

We estimated Fecundity within each location as the average annual number of eggs laid, determined from a pre-existing dataset that describes thermal sensitivity of oviposition of the Lepidopteran pest Eldana saccharina (Pyralidae), in which 205, 417, 432 and 183 eggs were laid, per female per day, at $15,20,25$, and $35^{\circ} \mathrm{C}$ respectively (Eq. (6); Kleynhans et al., 2018; Way, 1995). For each generation throughout the simulation, we assumed that oviposition occurred on the final day of the adult phase. On this particular day, if there was no thermal or desiccation stress encountered, the number of eggs laid was dependent on the mean temperature $\left(T_{a}\right)$, whereby:

Fecundity $=\left\{\begin{array}{c}-2.522 T_{a}^{2}+124.42 T_{a}-1085.5, L D T \leq T_{\min } ; U D T \\ \geq T_{\max } ; D S=0 \\ 0, L D T \geq T_{\min } ; U D T \leq T_{\max } ; D S=1\end{array}\right.$

The total number of eggs produced throughout the entire simulation period ( $\sum$ Fecundity) at each location was then tallied (Fig. 1), and subsequently incorporated into Eq. (2) to attain the overall measure of population performance.

\subsection{Model simulations}

At each location across the modelling landscape, if Survival $=1$ (Eq. (5)) and at least one generation could be completed each year (Voltinism $\geq 1$ ), the climate at that particular site was deemed to be suitable for occupancy (Fig. 1). If three of the five CMIP5 model datasets predicted occupancy of a grid cell (i.e. $>50 \%$ model agreement), then that grid cell was included in the species' range (Supplementary Material; Fig. A. see Araujo and New, 2006). To predict population performance, we ran separate simulations for each CMIP5 modelling dataset, and then averaged the performance predictions from the five models for each grid-cell.

\subsection{Statistical analyses}

Differences in the total occupancy (distribution size) of the different species under either the current or the future climate scenarios were compared using a generalized linear model (GLM) with a quasi-poisson distribution of errors, constructed with the nlme package in $\mathrm{R}$ (Pinheiro et al., 2018; R Core Team, 2014). The model included "climate" scenario (current and future) and "species" (including both desiccation sensitive and tolerant forms of each, i.e. eight species in total) as fixed effects, with the total number of occupied locations of each species defined as the dependent variable.

We also used a GLM to determine how insect physiology affected predictions of population performance of the different species under current and future climate scenarios. Here, we included species and climate as fixed effects in the model, and to avoid any confounding effects due to pseudo-replication (with six species and two climate scenarios each location had a total of 16 predictions), we included site (or location) as a random effect. Significance values in the predicted overall occupancy and population performance among groups were corrected for false discovery rates using the Benjamini-Hochberg procedure (with the 'p.adjust' function in R).

We also built a series of models with the aim of describing how population performance differed across the latitudinal transect of Africa. We first calculated the mean predicted population performance from the model outputs within each $1^{\circ}$ latitudinal band. With these averaged data (the dependent variable), we built a series of general additive models (GAMs) and GLMs that included different combinations of parameters for species and latitude (Supplementary Material; Table A.2). We then compared the outputs of these models, and determined the model of best fit according to that with the lowest Bayes Information Criterion (BIC) value (more appropriate than the $A I C$ for models of datasets with large sample sizes; Acquah, 2010). To this end, the model best describing the latitudinal patterns was found to be a GLM and included as parameters: species, latitude with a second degree polynomial term (i.e. latitude-squared, which we interpret as distance from the equator), as well as an interaction between species and latitude. This procedure was first performed with data from the current climate predictions, and then repeated with the predicted changes in this performance under the future climate scenario (i.e. future performance - current performance; Supplementary Material; Table A.2).

\subsection{Model validation}

To assess the applicability of the modelling framework we considered two Lepidoptera distributed across Africa for which physiological and distribution information are available. Briefly, datasets describing the thermal sensitivity of each species were sourced from previous studies and directly incorporated as input variables into the model (Supplementary Material; Table A.3). Model simulations with the 2011-2015 climate data were conducted according to the methods described above, and predictions of the species distributions mapped across the landscape. These predictions were subsequently validated against species observation records also sourced from the literature.

\subsubsection{Busseola fusca}

The African stem borer Busseola fusca (Fuller) is a major pest on maize, sorghum and sugarcane (Kfir et al., 2002). As a consequence, this species has been the subject of a number of studies describing its environmental tolerances (Khadioli et al., 2014b; Usua, 1968), as well as the potential for the species to spread into novel agricultural regions using both correlative (Maxent) and hybrid (CLIMEX) SDM approaches (Dupas et al., 2014; Hauptfleisch et al., 2014). We incorporate previously published datasets of degree-day requirements, developmental temperature thresholds and critical thermal limits (Khadioli et al., 2014b; Usua, 1968; Supplementary Material; Table A.3) as inputs in the model. Given that the pest is usually intercepted in irrigated locations we assume that the species does not encounter days of low water availability (Dupas et al., 2014; Hauptfleisch et al., 2014), and so we ran these simulation without desiccation stress (i.e. we excluded the desiccation component of the model). We modelled this species across the full African continent at a resolution of $1^{\circ}$, according to the methods described above. Observation records of the species were sourced from a previous study that developed correlative (Maxent and regression) models of the species (Dupas et al., 2014; note that only presence records were used here).

\subsubsection{Bicyclus anynana}

The squinting bush-brown butterfly, Bicyclus anynana (Butler) is another commonly-studied lepidopteran endemic to sub-Saharan Africa (Larsen, 2011). It has previously been used as a model organism to explore the evolution of developmental and life-history strategies in insects, including how environmental parameters, such as temperature, affect physiological traits (Oostra et al., 2011; Pijpe et al., 2007; van den Heuvel et al., 2013), making it an ideal candidate for our modelling approach. To model this species' distribution we incorporated published measurements on the species development rates (degree-day requirements) and survival at different temperatures (Fischer et al., 2010; Oostra et al., 2011; taking a mean of the dry- and wet- season 
morphs; Supplementary Material; Table A.3), and assuming that each life-history stage was sensitive to desiccation stress (where 60 days with low rainfall induces mortality, see definition above). Although $B$. anynana is present in central and eastern Africa (de Jong et al., 2011; Larsen, 2011), we were unable to access sufficient numbers of georeferenced observation records of the species within these countries for model validation. However, a comprehensive set of observations records from South Africa, Lesotho and Swaziland could be accessed from an online Virtual Museum database (LepiMAP, 2014). Thus, although we ran the model across all southern African countries, we validated its predictions with these latter three countries only at a resolution of $1^{\circ}$. Although this is only a part of the full range, it includes sub-tropical, temperate, montane, and arid ecotones, providing a suitably varied background across which to test how the species' thermal sensitivities constrain the southern boundary of the species known range.

For each species, we predicted survival according to the restrictions described above, generating a binary distribution map (presence $=1$; absence $=0$ ). From these predictions 10,000 background points were selected to represent "pseudo-absence" sites (Phillips et al., 2006). These background points were selected at random across the landscape (irrespective of whether or not there was an observation record for a grid cell) to avoid any bias due to pseudo-absence (Phillips et al., 2006). The model distribution predictions were then compared against these presence/background data to calculate the area under the receiver operating curve (AUC; Swets, 1979) using the pROC package in $\mathrm{R}$ (Robin et al., 2011). Due to the relatively small extent across which the model was validated for $B$. anynana (number of grid cells $=451$ ), we repeated this procedure with 100, and 1000 background points, each cross-validated 100 times. These values did not differ significantly from one another, supporting the validity of our B. anynana modelling approach (Supplementary Material; Table A.4).

\section{Results}

\subsection{Species occupancy under current and future climates}

The predicted distributions for each of the hypothetical species were centered on the tropical regions of the African continent, and were more dependent on the range of thermal tolerance than on development rates (Fig. 2). Indeed, species with a broad thermal tolerance occupied approximately $60 \%$ more locations than species with a narrow thermal tolerance $\left(\mathrm{F}_{7,15}=45.2 ; \mathrm{p}<0.001\right.$; Fig. $2 \mathrm{a}$, b). Developing at a slow rate posed no additional constraints on survival for the species with narrow thermal tolerance (Fig. 2b, d). For the species with a broad thermal tolerance, there was only one location within which the insect could not persist if it was set to develop at a slow, as opposed to a fast, development rate (Fig. $2 \mathrm{a}, \mathrm{c}:-0.5^{\circ} \mathrm{S}, 36.5^{\circ} \mathrm{W}$ ). When sensitivity to desiccation was included in the model, the total predicted occupancy of all four species declined: species occupancy contracted by $74 \%$ and $62 \%$ for the thermally-tolerant and -sensitive species respectively (Fig. 2).

Under the future climate scenario (2046-2050), the predicted occupancy of all four species significantly declined $\left(\mathrm{F}_{1,15}=22.9\right.$; $\mathrm{p}<0.05$ ). Irrespective of development rate, occupancy of the species with a narrow thermal tolerance declined to a greater extent (54\%, Fig. 3a) than that of the more thermally tolerant species (28\%, Fig. 3d). Including the additional constraint of desiccation sensitivity resulted in a less severe reduction in occupancy with climate change, declining by $35 \%$ and $7 \%$ for the thermal sensitive and tolerant species respectively (Fig. 3). This latter result is likely due to the relatively lower occupancy of the desiccation-sensitive species under the current climate (Fig. 2), in comparison to that of the desiccation-tolerant species.

While climate change led to an overall decline in occupancy, there were nonetheless regions into which species distributions were predicted to expand in the future (Fig. 3c, f). Depending on the species, contractions to the current distributions were driven by a rise in temperature beyond the $C T_{\max }$, a drop below $C T_{\min }$ and, when desiccation was included in the model, increasingly dry conditions (Fig. 3b, e). As expected, range contractions due to thermal stress (primarily high temperatures) were more severe for the species with a narrow thermal tolerance range (Fig. 3d). Regions into which the species' distributions could expand under the future climate were primarily due to an increase in temperature, such that $T_{\text {min }}$ no longer fell below the assigned species $C T_{\min }$ (Fig. 3c, f), occurring more readily for the species with a narrow thermal tolerance (Fig. 3f). When desiccation sensitivity was included, future distribution expansions were also facilitated by more frequent rainfall events in some regions (Fig. 3c, f). Finally, contractions and expansions of species distributions were driven by multiple processes within the same latitudinal bands albeit independent of one another.

\subsection{Population performance under current and future climates}

Although developmental physiology had minimal impacts on the occupancies of the species, it had a substantial influence on their predicted population performances. Predicted population performances of the fast-developing species were approximately $63 \%$ higher than their slow-developing counterparts $\left(\mathrm{F}_{1,37950}=33,128 ; \mathrm{p}<0.0001\right.$; Fig. $4 \mathrm{a}$, d). Among these life-history strategies, species with a broad thermal tolerance performed approximately $41 \%$ higher than those with a narrow thermal tolerance. Including sensitivity to desiccation in the model led to a further $23 \%$ decline in population performance (Fig. $4 \mathrm{~b}$, e).

Under the future climate scenario population performance of all species declined, although the extent of these declines varied among species (Species $\times$ Climate: $F_{7,37950}=463$; $p<0.0001$; Fig. 4c, f). Population performance of the species with a narrow thermal tolerance declined by $38 \%$ in comparison to current conditions, while thermal tolerant species appeared to be more robust to future temperatures (performance declined by approximately 16\%). Climate change affected species with slow and fast developmental physiologies in a similar manner (fast development proved to be slightly more vulnerable than slow development). Imposing the additional constraint of desiccation caused population performance to decline slightly further, which was less severe for the species with a broad (16\% further decline), than narrow (14\% further decline) thermal tolerance (Fig. 4c, f, note absolute predicted values of change presented in Figure).

Across the landscape, performance was generally highest in tropical regions and declined asymmetrically with increasing latitude (Latitude ${ }^{2}: \mathrm{F}_{1,2528}=3979.7 ; \mathrm{p}<0.001$; Fig. 4b, e), although the extent of these declines varied among species (Latitude $\times$ Species: $\mathrm{F}_{7,17704}=1034.9 ; \mathrm{p}<0.001$ ). Population performance of the four desiccation sensitive species decreased most severely across mid-latitudinal bands $\left(20^{\circ}-30^{\circ}\right.$ latitude) in the northern hemisphere (Fig. $\left.4 \mathrm{~b}, \mathrm{e}\right)$. Similar patterns were observed in predicted performance under the future climate scenario (Latitude $\times$ Species: $\quad F_{7,17703}=1222.0$; $\mathrm{p}<0.001$ ). It is worth noting here that we did not consider the impacts of altitudinal variation across the latitudinal gradient of the continent. Highlands are prevalent across much of east Africa, and may partly account for the rapid decline in performance in these corresponding latitudes (approx. $10^{\circ} \mathrm{S}$ to $10^{\circ} \mathrm{N}$ ). Desiccation-sensitive species incurred the greatest decline in performance within latitudes that encompass arid biomes (Fig. 4c, f; e.g. $15^{\circ} \mathrm{N}-25^{\circ} \mathrm{N}$ ). This is likely due to high temperature and low water availability under future conditions, both of which inhibit development and survival (see Eqs. (1) and (5)).

\subsection{Model choice and performance}

It is generally accepted that models with an AUC value above 0.7 perform moderately well and significantly better than random, while those over 0.8 have good predictability (Elith, 2006). Validating our model's predictions of Bicyclus anynana distribution against observation 


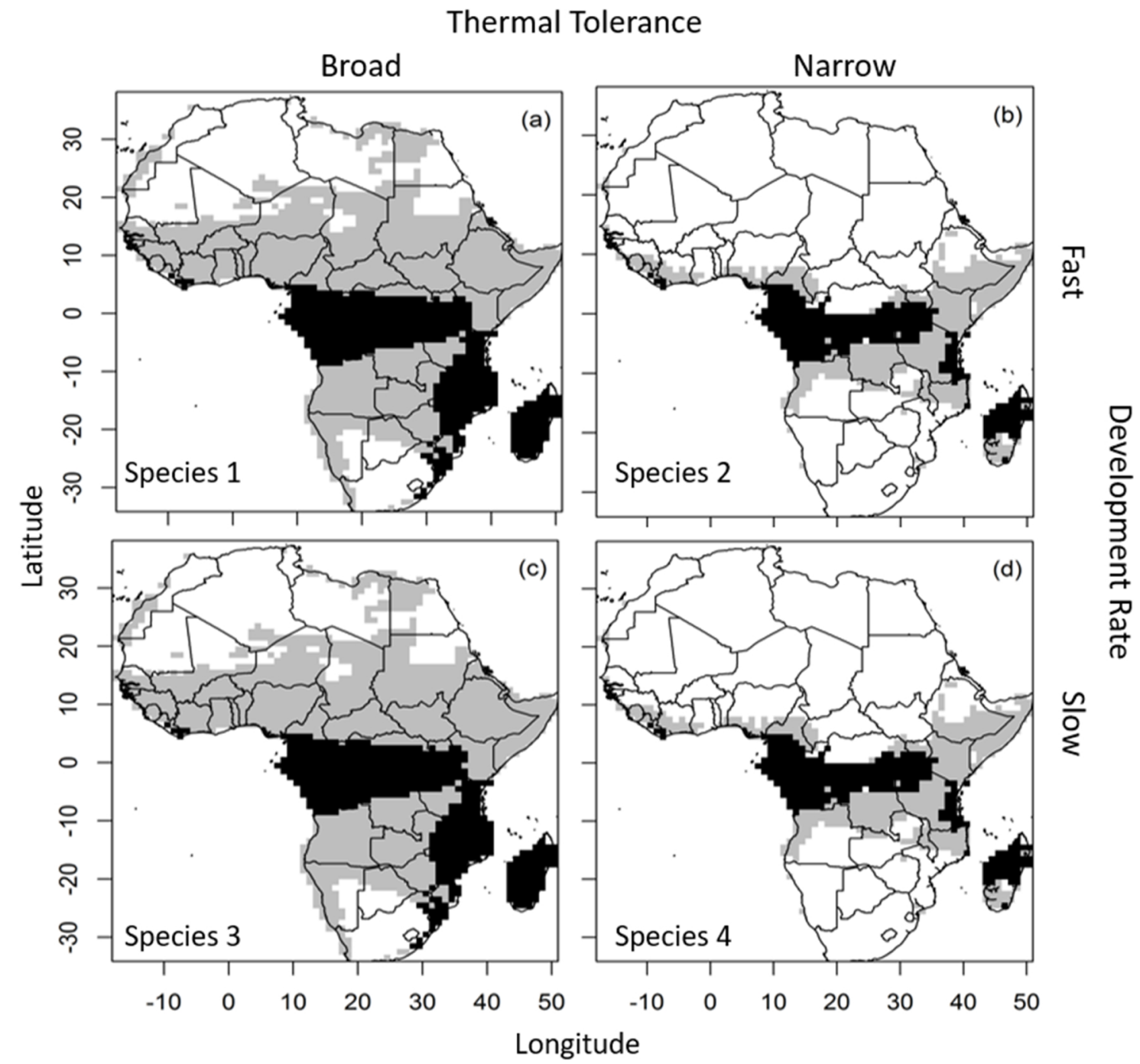

Fig. 2. Species distributions predicted for the current climate (2011-2015) of four hypothetical Lepidoptera species (thermal tolerance and development rate indicated on top and right sides of panels, respectively; see Table 1 for details on species parameters), with temperature constraints only (grey) and with additional sensitivity to desiccation (back).

records of the species indicated good predictability, with an AUC of 0.865 (95\% CI \pm 0.841-0.888; Fig. 5a). The model predicting occupancy of Busseola fusca performed moderately well, and significantly better than random, with an AUC of 0.715 (95\% CI \pm 0.655-0.782; Fig. 5b).

While the summation of degree-day units is a relatively rudimentary approach for tracking a species development and phenology, the existence and readily available information on degree-days for many species (particularly agricultural and forestry pest insects) ensures that the model presented here remains applicable to a range of different species. Comparisons of this linear development trajectory with more complex thermal-response models (Logan (Logan, 1976) and non-linear Lactin functions (Lactin et al., 1995)) did not generate predictions that varied substantially from this technique (Supplementary material B).

\section{Discussion}

An insect's geographic distribution is likely to be a consequence of long-term responses to multiple abiotic stressors, and the nature of these stressors will likely change with climate change (Todgham and Stillman, 2013). Whereas correlative climate envelope models account for multiple variables, they tend to gloss over the possibility of stressors changing independently of one another. By contrast, mechanistic models can explicitly account for such changes, if they occur. We pilot this approach with hypothetical but physiologically-realistic Lepidoptera species, which allows us to partition the effects of biology and multiple stressors in driving responses to climate change. We show that thermal tolerance breadth contributes to both current and future distribution, more so than developmental requirements. However, the broad distribution of thermally-tolerant species is truncated substantially when the species' potential sensitivity to desiccation is taken into account, highlighting the importance of including water availability and water balance physiology when considering insect responses to climate change.

Recent broad-scale analyses have highlighted the susceptibility of tropical terrestrial ectotherms to climate change (e.g. Deutsch et al., 2008; Huey et al., 2009; Clusella-Trullas et al., 2011; Hoffmann et al., 2013). This sensitivity is thought to arise because tropical species living at high temperatures have a lower thermal safety margin than their temperate counterparts (Deutsch et al., 2008): the exponential shape of the metabolic rate-temperature curve means that small variations at warmer temperatures have a more pronounced impact than equivalent variation at lower temperatures where the curve is flatter, (i.e. Jensen's inequality; Dillon et al., 2010), and because they have less capacity to further increase their thermal tolerance (Deutsch et al., 2008; Kellermann et al., 2012). In our models, we show that the (quasi- 


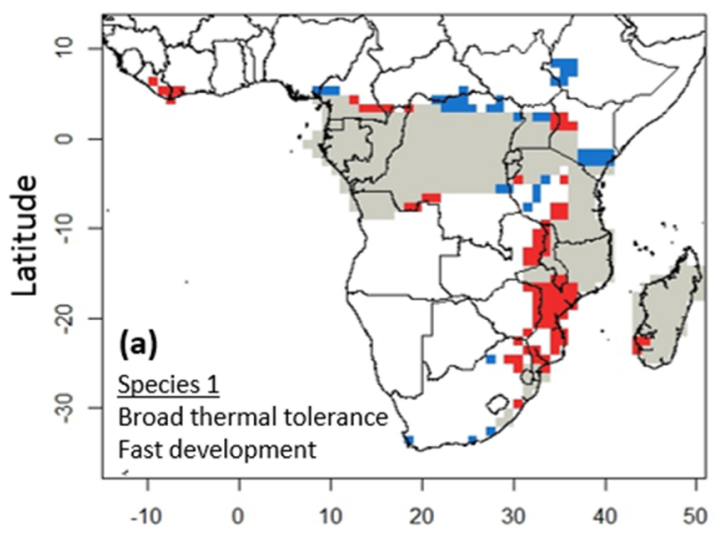

\section{(b) Range Contraction (c) Range Expansion}
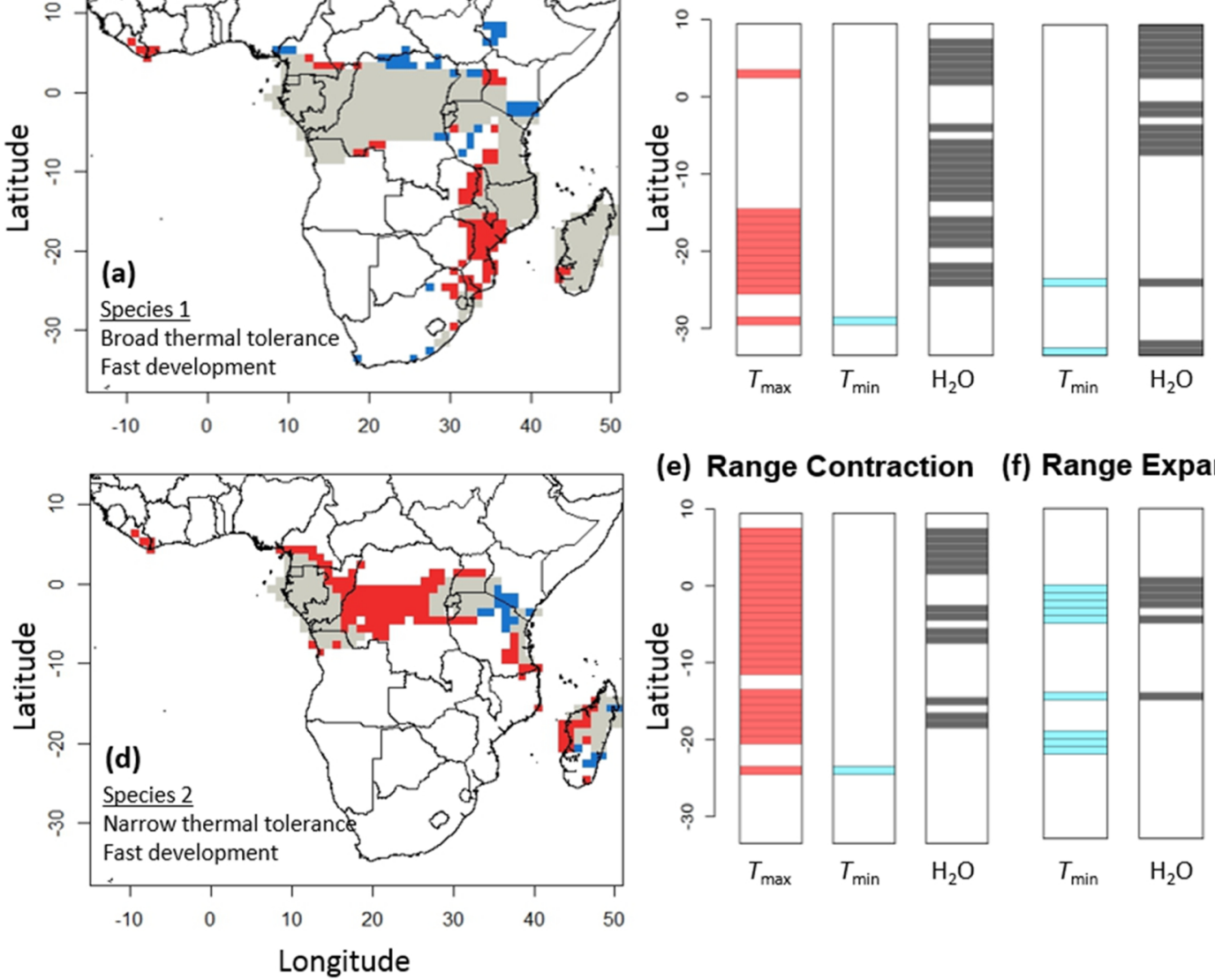

(e) Range Contraction

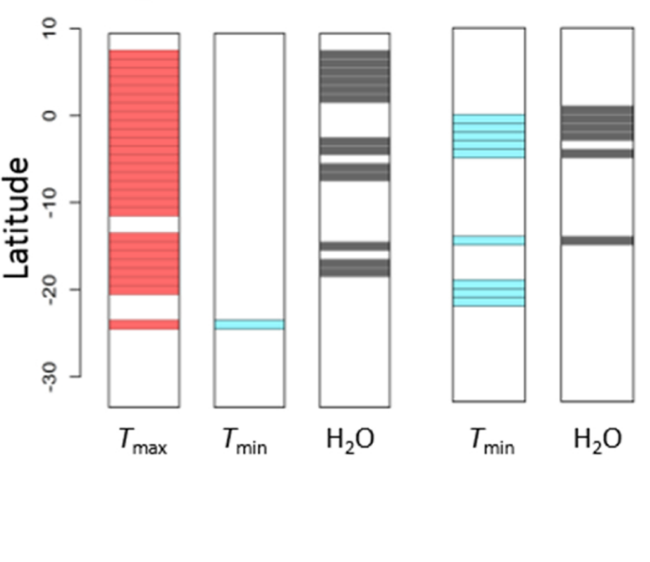

(f) Range Expansion

Fig. 3. Changes in the predicted species distributions between current and the future climate change scenario for the fast developing with broad- (a; Species 1 ), and narrow- (d; Species 2) thermal tolerances, with sensitivity to desiccation included. Regions with a range contraction (red) and range expansion (blue), while cells in which the species are predicted to persist under the future climate scenario (grey) are shown. Neither species could persist above $10^{\circ} \mathrm{N}$, so this region is not included. The underlying drivers that give rise to these range contractions ( $b$ and e) or expansions (c and $f$ ) within each latitudinal band are shown in bars adjacent to each map. Latitudinal bands in which species ranges were predicted to contract were associated with increased incidence of $T_{\max }$ above the $C T_{\max }$ (red) or $T_{\min }$ below the $C T_{\min }$ (blue), or increased desiccation stress (dark grey). By constrast, range expansions were due to reduced incidence of $T_{\min }$ below the $C T_{\min }$ (blue) and reduced desiccation stress (dark grey) (For interpretation of the references to colour in this figure legend, the reader is referred to the web version of this article).

tropical) species with a narrow thermal tolerance (akin to the maize stem borer Chilo partellus; Khadioli et al., 2014a) persisted in 54\% of its current distribution with predicted climate change, whereas the species with a broad thermal tolerance (and consequently a broader starting distribution) lost $72 \%$ of its current distribution under climate change, perhaps because it began with a broader distribution. Thus, we find little support, based primarily on thermal limits, for the widely-held notion that tropical species will be disproportionately susceptible to climate change on the basis of their narrow thermal limits.

When we incorporate desiccation sensitivity into our models, the impacts of climate change on species performance are reduced, and the direction of predicted species range shifts are not typical of the poleward shifts expected if species are tracking temperature change alone (Parmesan et al., 1999). Specifically, species with a narrow thermal tolerance and the added constraint of desiccation incur range contractions in inland regions of the current predicted range, such that the species is predicted to occupy a more coastal distribution in the future. By contrast, the species with a broad thermal tolerance is predicted to undergo range contractions in the southern hemisphere, but expands into relatively higher latitudes in the northern hemisphere as a function of predicted increases in rainfall frequency. These asymmetrical and coastal shifts in the species occupancy across the landscape reflect the shifting distributions of species that are tracking changes in precipitation as well as temperature (Crimmins et al., 2011; Lenoir and Svenning, 2015; VanDerWal et al., 2012) or changing associations between climate and climate-related traits through either adaptive evolutionary or non-adaptive processes (e.g. behavioural constraints). Indeed, wholesale poleward shifts in geographic ranges are increasingly questioned in insect responses to climate change (Helmuth et al., 2002; Hill et al., 2016). In the context of insect pests, understanding how of artificial crop irrigation directly affects species performance and distribution, or might serve to buffer climate impacts, needs further empirical exploration. Nonetheless, predictions of insect responses to climate change that are based only on temperature alone may be largely incorrect, because of the significant role of water availability in determining local population abundances which translates to variation in broader geographic distribution.

\subsection{Unpacking drivers of responses to climate change}

The bottom-up modelling approach employed here allows us to unpack the underlying drivers of the range expansions and contractions of our different hypothetical (but realistic) species in the future. Range expansions in the species with a narrow tolerance, for example, arise in most latitudes due to warmer minimum temperatures and more frequent rainfall events, and these drivers largely occur simultaneously. In contrast, range contractions arise through both extreme high temperatures and an increase in periods without rain. At some latitudes, increases in these stressors co-occur (e.g. 28 locations for Species 2), while at others they occur independently of the other (e.g. 96 locations 


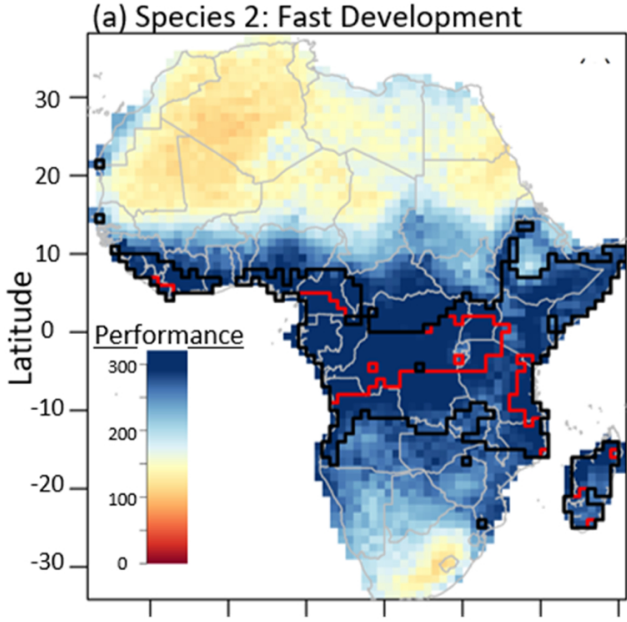

(d) Species 4: Slow Development

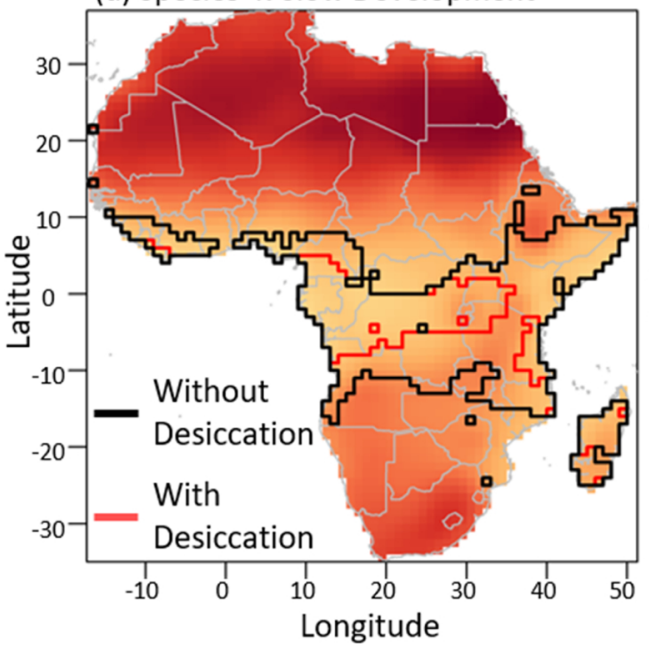

Population performance

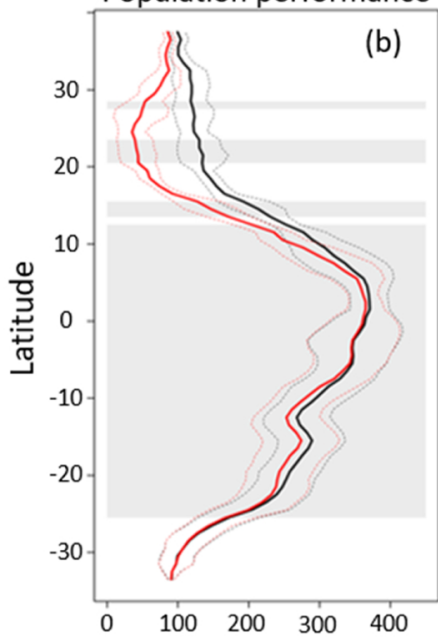

(b)
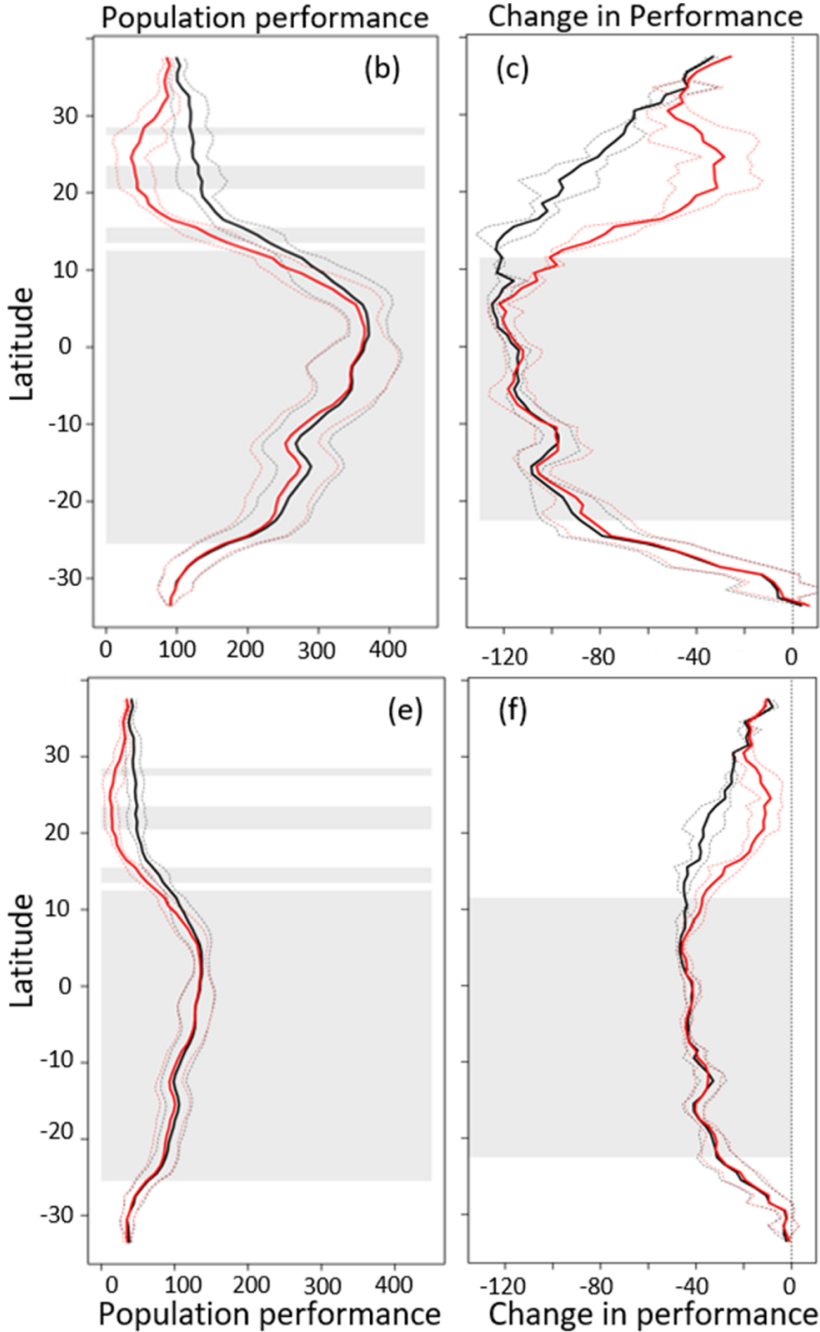

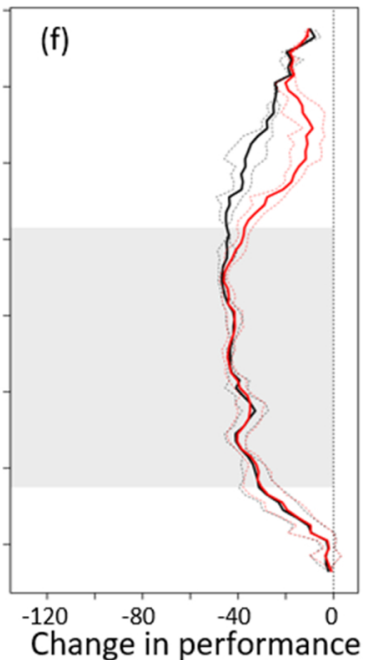

Fig. 4. Predictions of the population performance metric (a product of survival and fecundity, see Eq. (2)) for species with a narrow thermal tolerance and fast (a; Species 2) or slow (d; Species 4) development rate, with the predicted occupancy of the species with and without desiccation included, indicated in the red and black lines respectively. Average predicted population performance (arbitrary units) within each $1^{\circ}$ latitudinal band is shown in the adjacent plots (b, e; black lines). Including desiccation (b,e; red lines) reduced the relative performance metric of both species across mid-latitudinal regions. Changes in predicted performance (future performance metric - current performance metric) (c, f) varied in a non-uniform manner across latitude. Dotted lines represent the $95 \%$ confidence interval in performance within each latitudinal band, and shaded areas (b, c, e and f) correspond to latitudes with predicted potential occupancy. (For interpretation of the references to colour in this figure legend, the reader is referred to the web version of this article).

due to only heat stress for Species 2). The non-uniform manner of these environmental changes across the landscape may influence a species' survival in different ways, particularly where resistance to the different stressors have co-evolved (Todgham and Stillman, 2013). For simplicity, here we assume that these stressors cause mortality independently of one another (Eqs. (3)-(5)), however many species exhibit cross-tolerance (or cross-talk) where the induction of one stress response relies on, or elicits, the activation of the other (Sinclair et al., 2013; Gotcha et al., 2018), or have seasonal variation in their tolerances, which may trade off among stressors (Hoffmann et al., 2005; Terblanche et al., 2006). The decoupling of critically high temperatures and desiccation stress for the broad thermal tolerant species, for example, may simultaneously heighten sensitivity to the otherwise benign stressor. Such processes can be further explored with the modelling framework developed here, but were beyond the scope of the present study.

Here, for simplicity, we constrain the predicted occupancy of our species to locations where temperatures never exceed the critical thermal limits (i.e. Survival in Eq. (5) is equal to one), and at least $0.1 \mathrm{~mm}$ of rain within a 60 day period. While this provides a relative measure of species' vulnerability to climatic stress, in reality insect mortality beyond the critical temperature and desiccation thresholds is far more nuanced. For example, most insects readily survive exposure to $C T_{\text {min }}$, and often much lower temperatures (Bale, 1987; Zachariassen, 1985), and both cold and heat tolerance can be further enhanced by entry into diapause (Tauber and Tauber, 1976). Temperate species have adapted a number of strategies to dealing with cold conditions, while tropical species (that are rarely exposed to low temperatures) tend to be chill-susceptible, and mortality is thus a product of temperature and time (Nedvĕd et al., 1998; Renault et al., 2004). In this study, relaxing mortality thresholds for both types of species is likely to lead to expansions in the species predicted occupancies, under both current and future climate scenarios.

Simply predicting an organism's presence or absence can overlook more subtle changes in species' responses to climate change (Ashcroft et al., 2017), which we attempted to encompass in our predictions of population performance. The asymmetrical distribution shift of Species 1 with climate change is further reflected in predictions of population performance of all of our different hypothetical species. The areas in which species' performance was most severely compromised appeared to correspond to the Sahara and Namib Deserts, with less-compromised populations towards the southern coast of South Africa. This variation in predicted performance across the landscape further highlights the 

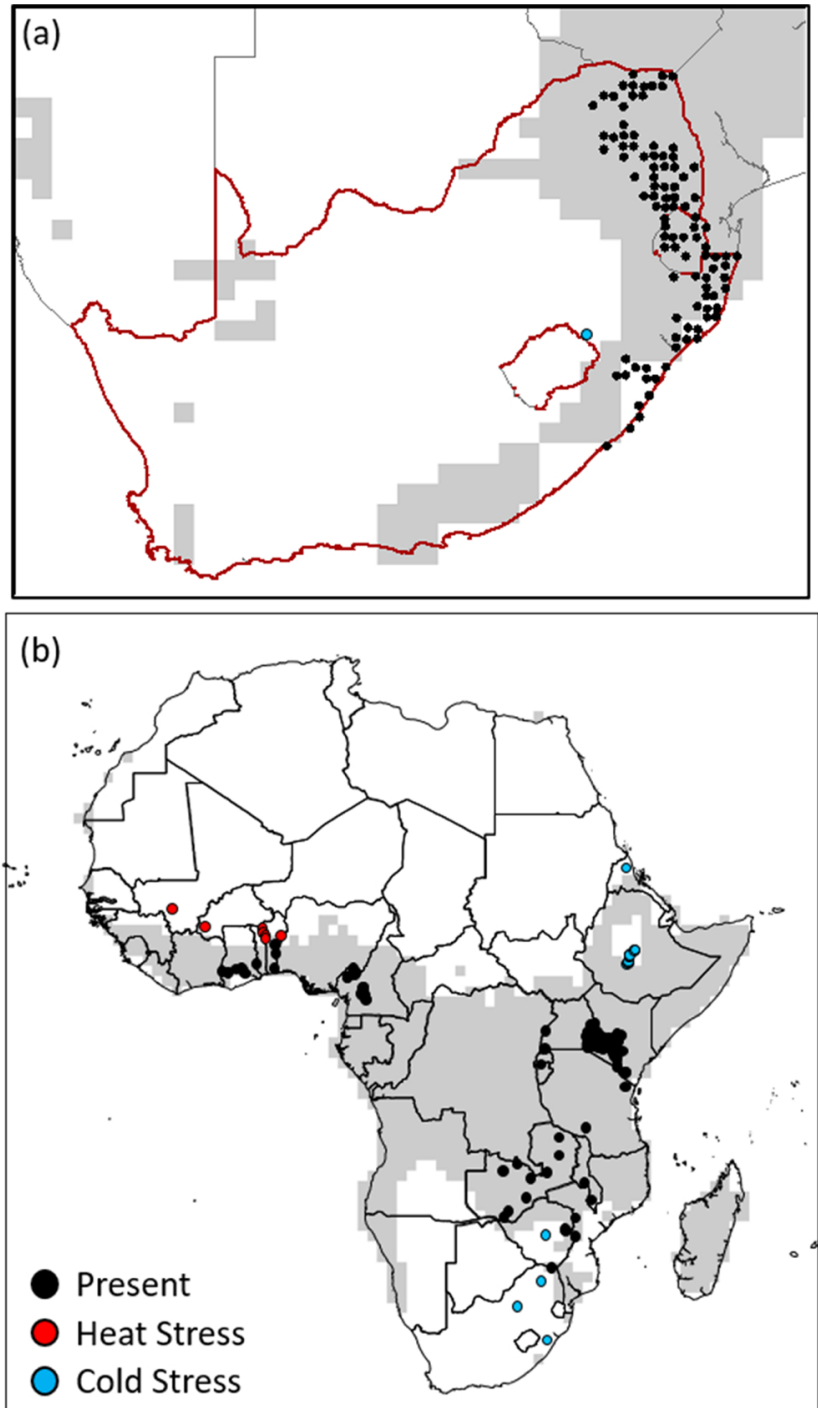

Fig. 5. Validations of model predictions against observation records of (a) Bicyclus anynana and (b) Busseola fusca. The predicted distribution under current conditions (grey) and presence records (black) for each species are shown. Locations where the predicted mortality of $B$. fusca due to heat stress (red) and cold stress (blue) are indicated. The model predictions for $B$. anynana were validated only across South Africa, Lesotho and Swaziland, outlined in red. Note that black observation records of $B$. anynana along the coast of South Africa, where an apparent absence is predicted, fall outside the modelling extent (no climate data were available for this site) (For interpretation of the references to colour in this figure legend, the reader is referred to the web version of this article).

local specificity of insect responses to climate change. While the latitudinal transect considered here does not extend beyond $35^{\circ}$ either side of the equator, the non-uniform response indicates that assessing species vulnerability as a simple temperate vs tropical comparison overlooks important complexities (Deutsch et al., 2008; Bonebrake and Mastrandre, 2010).

In our model, we make several assumptions about insect responses to stressors. First, we assume a linear relationship between mortality and temperature beyond the $C T_{\max }$ and $C T_{\min }$. This captures the frequency of thermal stress events and reflects among-individual performance, which we argue is an improvement over treating these limits as a "hard limit" on survival (cf. Deutsch et al., 2008). Such mortality rates beyond the critical limits however, often depend on thermal history, depending on an organisms' ability to mount a compensatory response (i.e. phenotypic plasticity) to prior stress (Sgro et al., 2016) - or the negative consequences of stress accumulation with repeated exposure (Marshall and Sinclair, 2009, 2015). It would be possible to modify the model to reflect these complexities, while the response to temperatures below the $C T_{\min }$ possibly also requires a duration of exposure component (Sinclair et al., 2015). Our model could be further extended to reflect responses by other life-history traits such as growth, fecundity and longevity, and interactions among these traits (Bubliy and Loeschcke, 2005; Rohmer et al., 2004; Sinclair et al., 2016). Finally, we could again extend the model to include diapause (Danks, 2007; Tauber and Tauber, 1976) to reflect species that use this strategy to avoid unfavourable conditions. Such modifications will be most appropriate for application to a particular focal species of particular interest based on empirical input data, so extending the model to encompass these possibilities is beyond the scope of the current work.

One limitation of the fine temporal resolution is the higher uncertainties associated with climate model projections. Previous studies have confirmed that GCM model predictions run through different experiments in the CMIP5 database do vary, and this variation is likely exacerbated in daily, as opposed to monthly, outputs (Tierney et al., 2015). Although we ran each of the five climate model iterations (Supplementary Material; Table A.1) for five consecutive years to reduce biased predictions arising from inter-annual climate anomalies, there was considerable variation among the final model outputs. Predicted overall occupancy varied between the five GCM models by between $51 \%$ and $87 \%$ among iterations, depending on the species in question (Supplementary Material; Fig. A.1). Deviations in predicted performances between model iterations also varied across the landscape, with arid conditions in mid-latitudinal regions of the continent generating the most variable predictions among models (Supplementary Material; Fig. A.2). High uncertainty in this region is likely associated with the difficulties in predicting rainfall events, and is consistent with previous studies that have taken a similar modelling ensemble approach (Clark et al., 2016; Dai and Zhao, 2016; Wright et al., 2015). The variation among model iterations here highlights the importance of considering multiple climate modelling experiments when extrapolating SDMs into future climate change scenarios (Araujo and New, 2006; Tierney et al., 2015).

Modelling future precipitation patterns is challenging, particularly at high temporal resolutions (Clark et al., 2016; Dai and Zhao, 2016; Wright et al., 2015). These uncertainties are exacerbated when trying to extrapolate to the humidity environment experienced by the insect (Potter et al., 2013; de la Vega and Schilman, 2017), and this is perhaps why the majority of studies that seek to describe climate change responses focus on the impacts of temperature. Moreover, terrestrial insects can obtain water from food, fog, dew, ground-water in the soil, or from general runoff (McLaughlin et al., 2017), and spatial variation in these water sources is likely decoupled and buffered from the broadscale measures of precipitation we used. Indeed, water availability in irrigated regions will be almost entirely buffered from climatic predictions of rainfall. Essentially, these regions might be best reflected in our models of species that are not susceptible to desiccation stress, however additional parameters that describe irrigation could be included to provide more realistic predictions of pest species occupancy and performance (Hauptfleish et al., 2014; de Villiers et al., 2016, 2017). While translating the macroclimatic GCM projections into microclimates typically encountered by insects (Barton et al., 2014; Pincebourde and Woods, 2012) will require an even finer spatial and temporal resolution, we have nonetheless made some progress beyond the long-term average precipitation measures used in previous modelling studies (Elith et al., 2006; Helmuth 2014; but see Kearney and Maino, 2018).

Previous studies that employ correlative and hybrid SDMs (such as Maxent and CLIMEX) to explore the impacts of climate change on agricultural pests in Africa predict either little change, or an overall increase in habitat suitability with climate change (Biber- 
Freudenberger et al., 2016; Kumar et al., 2015; Tonnang et al., 2017; Deutsch et al., 2018; Lehmann et al., (in review)). By contrast, our model predicts an overall decline in population performance across the full modelling extent. The performance metric calculated here is specifically defined to take advantage of the fine temporal resolution, accounting for the daily temperature extremes and real-time periods of drought. As a consequence, the higher temperatures predicted under the future climate scenario have resulted in more hours during which mortality was incurred and development was delayed (Eqs. (3) and (1)). This delayed development in turn decreased voltinism and fecundity, and combined with reduced survival, led to an overall decline in performance (Eq. (2)). Thus, our results differ from previous studies based on average long-term climate parameters (Biber-Freudenberger et al., 2016; Tonnang et al., 2015), likely because we are deliberately capturing the short-term responses of insects to their environment, and allowing extremes, variability, and means of temperature and precipitation to decouple.

\subsection{Model validity}

Increases in insect growth and development rates with rising temperature do not follow a simple linear trajectory, and more complex curvilinear techniques are unquestionably better approximates for these responses (Damos and Savopoulou-Soultani, 2012). However, the degree-day summation approach adopted here means that the model can be applied to a range of insect pests, for which degree-day information is readily available (Buckley et al., 2017, and references within). Integrating two curvilinear thermal development curves into the model (Logan et al., 1976; Lactin et al., 1995), did not significantly impact our findings: predicted distribution remained the same and performance varied only slightly in a generally uniform manner across the landscape (Supplementary Material B). We are therefore confident that the degree-day approach adequately captures insect survival and performance, while maintaining its broader applicability to multiple species and systems.

We developed the modelling framework on hypothetical Lepidoptera, but found that it performed relatively well when applied to "real" species: there was good predictability across both broad ( $B$. fusca), and narrow (B. anynana) geographic extents (Elith et al., 2006). There were some cases, however, where we failed to predict $B$. fusca occupancy (15 of 115 observations). Moreover, the model tended to over-predict the distributions of both species (high commission error). This latter error may in part be due to expansive regions across the continent where georeferenced records of species observations are unavailable, for example no species records of $B$. fusca could be accessed for the Democratic Republic of Congo, in spite of this country encompassing a large swathe of likely suitable habitat (Fig. 5). While these potential false-absences reduce the AUC values, the mechanistic foundation of the model ensures that they do not inherently bias its predictions (Beck et al., 2014; Kearney et al., 2008). An over-prediction of the species' distributions using this bottom-up modelling approach is not surprising, given we only account for a subset of key traits that likely contribute to their population dynamics: desiccation, temperature and developmental constraints on the species survival. Indeed, the opposite can be argued, that this illustrates the value of a mechanistic model to understand distributions of species in locations for which onthe-ground data are unavailable.

Despite these errors, our model predictions for B. fusca are consistent with previous CLIMEX model outputs (Hauptfleisch et al., 2014; Hill et al., 2016). However, unlike CLIMEX and correlative models, by explicitly defining the factors that constrain species survival there remains extensive scope for: 1) understanding how our assumptions affect the model predictions and: 2) incorporating additional parameters or processes to improve its accuracy. For example, in locations where $B$. fusca is observed but not predicted, mortality was caused by temperatures falling below the species' $C T_{\min }$ (eight locations in South Africa,
Eritrea and Ethiopia) or exceeding the $C T_{\max }$ (seven locations in western Africa, Fig. 5). These discrepancies may be a result of our relatively conservative definition for survival: if temperatures exceeded critical limits on just one day during the five-year simulation, an "absence" was predicted (Equation 3, see above), or reflect among-population variation in thermal tolerances (Sinclair et al., 2012). Moreover, B. fusca has an obligate larval diapause in response to cold conditions in the southern region of its current distribution (Kfir, 1988), precisely where our model failed to predict four observation records (Fig. 5b). Thus, incorporating diapause into this species model is likely to extend the species predicted distribution into these higher, cooler, latitudes.

\section{Conclusions}

Our model simulations highlight the importance of including a species' sensitivity to water availability, as well as thermal extremes, to accurately predict shifts in species distributions under future climate change scenarios. Moreover, in running model simulations at a fine temporal resolution, we show that extreme weather events in the future lead to an overall decline in population performance of our insects. The modelling framework developed here is particularly powerful as it provides not only an indication of the species' presence (or absence), but also how changes in climate will affect traits like population abundance, performance metrics such as foraging rates, and the timing of key life-cycle events (i.e. phenology). Explicitly defining species responses to temperature and desiccation stress, at a sufficiently high temporal resolution, will help to provide robust predictions as to how insects, including pests, pollinators, and vectors of disease, can be managed under future climates.

\section{Funding}

MGB was supported by a Claude Leon Foundation fellowship. BJS by a Discovery Grant from the Natural Sciences and Engineering Research Council (NSERC) of Canada. JST is supported by the South African National Research Foundation, Hortgro Science, and the DSTNRF Centre of Excellence for Invasion Biology.

\section{Acknowledgements}

This work began as part of a Society for Integrative and Comparative Biology symposium on 'Physiology in Changing Landscapes'. We thank Mhairi McFarlane for extensive discussion and feedback on drafts of the manuscript. We are grateful to the referees for comments that helped improve the manuscript.

\section{Appendix A. Supplementary data}

Supplementary material related to this article can be found, in the online version, at doi:https://doi.org/10.1016/j.ecolmodel.2018.12. 017.

\section{References}

Acquah, H.D., 2010. Comparison of Akaike information criterion (AIC) and Bayesian information criterion (BIC) in selection of an asymmetric price relationship. J. Dev. Agric. Econ. 2, 001-006.

Araujo, M., New, M., 2006. Ensemble forecasting of species distributions. Trends Ecol. Evol. 22, 42-47.

Ashcroft, M.B., King, D.H., Raymond, B., Turnbull, J.D., Wasley, J., Robinson, S.A., 2017. Moving beyond presence and absence when examining changes in species distributions. Glob. Change Biol. 23, 2929-2940.

Bale, J.S., 1987. Insect cold hardiness: freezing and supercooling - an ecophysiological perspective. J. Insect Physiol. 33, 899-908.

Barton, M.G., Porter, W.P., Kearney, M.R., 2014. Behavioural thermoregulation and its evolutionary consequences in a basking butterfly, Heteronympha merope. J. Therm. Biol. 41, 65-71.

Battisti, D.S., Naylor, R.L., 2009. Historical warnings of future food insecurity with unprecedented seasonal heat. Science $323,240-244$. 
Bebber, D.P., Ramotowski, M.A., Gurr, S.J., 2013. Crop pests and pathogens move polewards in a warming world. Nat. Clim. Change 3, 985.

Beck, J., Böller, M., Erhardt, A., Schwanghart, W., 2014. Spatial bias in the GBIF database and its effect on modeling species' geographic distributions. Ecol. Inform. 19, 10-15.

Biber-Freudenberger, L., Ziemacki, J., Tonnang, Z.E.H., Borgemeister, C., 2016. Future risks of pest species under changing climatic conditions. PLoS One 11, e0153237.

Bonebrake, T.C., Mastrandrea, M.D., 2010. Tolerance adaptation and precipitation changes complicate latitudinal patterns of climate change impacts. Proc. Natl. Acad. Sci. U. S. A. 107, 12581-12586.

Bonebrake, T.C., Boggs, C.L., Stamberger, J.A., Deutsch, C.A., Ehrlich, P.R., 2014. From global change to a butterfly flapping: biophysics and behaviour affect tropical climate change impacts. Proc. R. Soc. B 281 (2014), 1264.

Bubliy, O.A., Loeschcke, V., 2005. Correlated responses to selection for stress resistance and longevity in a laboratory population of Drosophila melanogaster. J. Evol. Biol. 18, 789-803.

Buckley, L.B., Huey, R.B., 2016. Temperature extremes: geographic patterns, recent changes, and implications for organismal vulnerabilities. Glob. Change Biol. 22, 3829-3842.

Buckley, L.B., Urban, M.C., Angilletta, M.J., Crozier, L.G., Rissler, L.J., Sears, M.W., 2010. Can mechanism inform species distribution models? Ecol. Lett. 13, 1041-1054.

Buckley, L.B., Arakaki, A.J., Cannistra, A.F., Kharouba, H.M., Kingsolver, J.G., 2017. Insect development, thermal plasticity and fitness implications in changing, seasonal environments. Integr. Comp. Biol. 57, 988-998.

Busby, J.R., 1991. BIOCLIM - a bioclimatic analysis and prediction tool. Plant Prot. Q. $6,8-9$.

Caminade, C., Kovats, S., Rocklov, J., et al., 2013. Impact of climate change on global malaria distribution. Proc. Natl. Acad. Sci. U. S. A. 11, 3286-3291.

Chen, I.-C., Hill, J.K., Ohlemuller, R., Roy, D.B., Thomas, C.D., 2011. Rapid range shifts of species associated with high levels of climate warming. Science 333, 1024-1026.

Clark, M.P., Wilby, R.L., Gutmann, E.D., et al., 2016. Characterizing uncertainty of the hydrologic impacts of climate change. Curr. Clim. Change Rep. 2, 55-64.

Clusella-Trullas, S., Blackburn, T.M., Chown, S.L., 2011. Climatic predictors of temperature performance curve parameters in ectotherms imply complex responses to climate change. Am. Nat. 177, 738-751.

Colinet, H., Sinclair, B.J., Vernon, P., Renault, D., 2015. Insects in fluctuating thermal environments. Annu. Rev. Entomol. 60, 123-140.

Coumou, D., Rahmstorf, S., 2012. A decade of weather extremes. Nat. Clim. Change 2, 491-496.

Crill, W.D., Huey, R.B., Gilchrist, G.W., 1996. Within- and between-generation effects of temperature on the morphology and physiology of Drosophila melanogaster. Evolution $50,1205-1218$.

Crimmins, S.M., Dobrowski, S.Z., Greenberg, J.A., Abatzoglou, J.T., Mynsberge, A.R., 2011. Changes in climatic water balance drive downhill shifts in plant species' optimum elevations. Science 331, 324-327.

Dai, A., Zhao, T., 2016. Uncertainties in historical changes and future projections of drought. Part I: estimates of historical drought changes. Clim. Change 144, 519-533.

Damos, P., Savopoulou-Soultani, M., 2012. Temperature-driven models for insect development and vital thermal requirements. Psyche 2012, 1-13.

Danks, H.V., 2007. The elements of seasonal adaptations in insects. Can. Entomol. 139, $1-44$.

de Jong, M.A., Wahlberg, N., van Eijk, M., Brakefield, P.M., Zwaan, B.J., 2011. Mitochondrial DNA Signature for Range-Wide Populations of Bicyclus anynana suggests a rapid expansion from recent refugia. PLoS One 6, e21385.

de la Vega, G.J., Schilman, P.E., 2017. Using eco-physiological traits to understand the realized niche: the role of desiccation tolerance in Chagas disease vectors. Oecologia 185, 607-618.

de Villiers, M., Hattingh, V., Kriticos, D.J., Brunel, S., Vayssières, J.F., Sinzogan, A., Billah, M.K., Mohamed, S.A., Mwatawala, M., Abdelgader, H., Salah, F.E.E., 2016. The potential distribution of Bactrocera dorsalis: considering phenology and irrigation patterns. Bull. Entomol. Res. 106, 19-33.

de Villiers, M., Kriticos, D.J., Veldtman, R., 2017. Including irrigation in niche modelling of the invasive wasp Vespula germanica (Fabricius) improves model fit to predict potential for further spread. PLoS One 12, e0181397.

Deutsch, C.A., Tewksbury, J.J., Huey, R.B., Sheldon, K.S., Ghalambor, C.K., Haak, D.C., Martin, P.R., 2008. Impacts of climate warming on terrestrial ectotherms across latitude. Proc. Natl. Acad. Sci. U. S. A. 105, 6668-6672.

Deutsch, C.A., Tewksbury, J.J., Tigchelaar, M., Battisti, D.S., Merrill, S.C., Huey, R.B., Naylor, R.L., 2018. Increase in crop losses to insect pests in a warming climate. Science 361, 916-919.

Dillon, M.E., Wang, G., Huey, R.B., 2010. Global metabolic impacts of recent climate warming. Nature 467, 704-707.

Dowd, W.W., King, F.A., Denny, M.W., 2015. Thermal variation, thermal extremes and the physiological performance of individuals. J. Exp. Biol. 218, 1956-1967.

Dupas, S., Le Ru, B., Branca, A., et al., 2014. Phylogeography in continuous space: coupling species distribution models and circuit theory to assess the effect of contiguous migration at different climatic periods on genetic differentiation in Busseola fusca (Lepidoptera: noctuidae). Mol. Ecol. 23, 2313-2325.

Elith, J., Leathwick, J.R., 2009. Species Distribution Models: ecological explanation and prediction across space and time. Annu. Rev. Ecol. Evol. Syst. 40, 677-697.

Elith, J., Graham, C., Anderson, R., et al., 2006. Novel methods improve prediction of species' distributions from occurrence data. Ecography 29, 129-151.

Fischer, K., Dierke, A., Franke, K., Geister, T.L., Liszka, M., Winter, S., Pflicke, C., 2010. Environmental effects on temperature stress resistance in the tropical butterfly Bicyclus anynana. PLoS One 5, e15284.

Gaines, S.D., Denny, M.W., 1993. The largest, smallest, highest, lowest, longest, and shortest: extremes in ecology. Ecology 74, 1677-1692.
Garcia, R.A., Burgess, N.D., Cabeza, M., Rahbek, C., Araujo, M., 2012. Exploring consensus in 21st century projections of climatically suitable areas for African vertebrates. Glob. Change Biol. 18, 1253-1269.

Gotcha, N., Terblanche, J.S., Nyamukondiwa, C., 2018. Plasticity and cross-tolerance to heterogeneous environments: divergent stress responses co-evolved in an African fruit fly. J. Evol. Biol. 31, 98-110.

Harcourt, D.G., 1969. The development and use of life tables in the study of natural insect populations. Annu. Rev. Entomol. 14, 175-196.

Harrison, J.F., Woods, H.A., Roberts, S.P., 2012. Ecological and Environmental Physiology of Insects. Oxford University Press, New York, USA.

Hauptfleisch, K.Y.T., Kriticos, D.J., Ota, N., 2014. InSTePP-HarvestChoice. Busseola fusca. Harvest Choice Pest Geography.

Helmuth, B., Harley, D.D.G., Haplin, P.M., et al., 2002. Climate change and latitudinal patterns of intertidal thermal stress. Science 298, 1015-1017.

Helmuth, B., Russell, B.D., Connell, S.D., et al., 2014. Beyond long-term averages: making biological sense of a rapidly changing world. Clim. Change Responses 1, 6-18.

Hijmans, R.J., van Etten, J., 2012. Raster: Geographic Analysis and Modeling With Raster Data. R Package Version 2.0-12. http://CRAN.R-project.org/package= raster.

Hijmans, R.J., Cameron, S.E., Parra, J.L., Jones, P.G., Jarvis, A., 2005. Very high resolution interpolated climate surfaces for global land areas. Int. J. Climatol. 25, 1965-1978.

Hill, M.P., Bertelsmeier, C., Clusella-Trullas, S., Garnas, J., Robertson, M.P., Terblanche, J.S., 2016. Predicted decrease in global climate suitability masks regional complexity of invasive fruit fly species response to climate change. Biol. Invasions 18, 1105-1119.

Hoffmann, A.A., Shirriffs, J., Scott, M., 2005. Relative importance of plastic vs genetic factors in adaptive differentiation: geographical variation for stress resistance in Drosophila melanogaster from eastern Australia. Funct. Ecol. 19, 222-227.

Hoffmann, A.A., Chown, S.L., Clusella-Trullas, S., 2013. Upper thermal limits in terrestrial ectotherms: how constrained are they? Flora - Morphol. Distrib. Funct. Ecol. Plants 27, 934-949.

Huey, R.B., Deutsch, C.A., Tewksbury, J.J., Vitt, L.J., Hertz, P.E., Álvarez Pérez, H.J., Garland, T., 2009. Why tropical forest lizards are vulnerable to climate warming. Proc. R. Soc. B. 282, 1-10.

IPCC, 2007. Climate change 2007: the physical science basis. In: Solomon, S., Qin, D., Manning, M., Chen, Z., Marquis, M., Averyt, K.B., Tignor, M., Miller, H.L. (Eds.), Contribution of Working Group I to the Fourth Assessment: Report of the Intergovernmental Panel on Climate Change. Cambridge University Press, Cambridge, UK and New York, NY, USA.

IPCC, Climate Change, 2014. Mitigation of climate change. In: Change, Climate, Edenhofer, O., Pichs-Madruga, R., Sokona, Y., Farahani, E., Kadner, S., Seyboth, K., Adler, A., Baum, I., Brunner, S., Eickemeier, P., Kriemann, B., Savolainen, J., Schlomer, S., von Stechow, C., Zwickel, T., Minx, J.C. (Eds.), Contribution of Working Group III to the Fifth Assessment Report of the Intergovernmental Panel on. Cambridge University Press, Cambridge, UK and New York, NY, USA.

Jackson, R.B., Le Quéré, C., Andrew, R.M., Canadell, J.G., Peters, G.P., Roy, J., Wu, L., 2017. Warning signs for stabilizing global $\mathrm{CO}_{2}$ emissions. Environ. Res. Lett. 12, 110202.

Kaunisto, S., Ferguson, L.V., Sinclair, B.J., 2016. Can we predict the effects of multiple stressors on insects in a changing climate? Curr. Opin. Insect Sci. 17, 55-61.

Kearney, M.R., Maino, J.L., 2018. Can next-generation soil data products improve soil moisture modelling at the continental scale? An assessment using a new microclimate package for the R programming environment. J. Hydrol. (Amst) 561, 662-673.

Kearney, M.R., Porter, W.P., 2009. Mechanistic niche modelling: combining physiological and spatial data to predict specie ranges. Ecol. Lett. 12, 334-350.

Kearney, M., Phillips, B.L., Tracy, C.R., Christian, K.A., Betts, G., Porter, W.P., 2008. Modelling species distributions without using species distributions: the cane toad in Australia under current and future climates. Ecography 31, 423-434.

Kellermann, V., Overgaard, J., Hoffman, A.A., Fløjgaard, C., Svenning, J., Loeschcke, V., 2012. Upper thermal limits of Drosophila are linked to species distributions and strongly constrained phylogenetically. Proc. Natl. Acad. Sci. U. S. A. 109, 16228-16233.

Kfir, R., 1988. Hibernation by the lepidopteran stalk borers, Busseola fusca and Chilo partellus on grain sorghum. Entomol. Exp. Appl. 48, 31-36.

Kfir, R., Overholt, W.A., Khan, Z.R., Polaszek, A., 2002. Biology and management of economically important Lepidopteran cereal stem borers in Africa. Annu. Rev. Entomol. 47, 701-731.

Khadioli, N., Tonnang, Z.E.H., Muchugu, E., et al., 2014a. Effect of temperature on the phenology of Chilo partellus (Swinhoe) (Lepidoptera, Crambidae); simulation and visualization of the potential future distribution of $C$. partellus in Africa under warmer temperatures through the development of life-table parameters. Bull. Entomol. Res. 104, 809-822.

Khadioli, N., Tonnang, Z.E.H., Ongamo, G., Achia, T., Kipchirchir, I., Kroschel, J., Le Ru, B., 2014b. Effect of temperature on the life history parameters of noctuid lepidopteran stem borers, Busseola fusca and Sesamia calamistis. Ann. Appl. Biol. 165, 373-386.

Kingsolver, J.G., Umbanhowar, J., 2018. The analysis and interpretation of critical temperatures. J. Exp. Biol. 221. https://doi.org/10.1242/jeb.167858.

Kingsolver, J.G., Woods, H.A., Buckley, L.B., Potter, K.A., MacLean, H.J., Higgins, J.K., 2011. Complex life cycles and the responses of insects to climate change. Integr. Comp. Biol. 51, 719-732.

Kleynhans, E., Terblanche, J.S., 2011. Complex interactions between temperature and relative humidity on water balance of adult tsetse Glossinidae, Diptera): implications for climate change. Front. Physiol. 2, 1-10.

Kleynhans, E., Barton, M.G., Conlong, D.E., Terblanche, J.S., 2018. Population dynamics of Eldana saccharina Walker Lepidoptera: pyralidae): application of a biophysical 
model to understand phenological variation in an agricultural pest. Bull. Entomol. Res. 108, 283-294.

Knox, J., Hess, T., Daccache, A., Wheeler, T., 2012. Climate change impacts on crop productivity in Africa and South Asia. Environ. Res. Lett. 7, 034032.

Kumar, S., Neven, L.G., Zhu, H., Zhang, R., 2015. Assessing the global risk of establishment of Cydia pomonella (Lepidoptera: tortricidae) using CLIMEX and MaxEnt niche models. J. Econ. Entomol. 108, 1708-1719.

Lactin, D.J., Holliday, N.J., Johnson, D.L., Craigen, R., 1995. Improved rate model of temperature-dependent development by arthropods. Environ. Entomol. 24, 68-75.

Larsen, T.B., 2011. Bicyclus anynana. The IUCN Red List of Threatened Species 2011. https://doi.org/10.2305/IUCN.UK.2011-2.RLTS.T160298A5360579.en. e. T160298A5360579.

Lenoir, J., Svenning, J.C., 2015. Climate-related range shifts - a global multidimensional synthesis and new research directions. Ecography 38, 15-28.

LepiMAP, 2014. The Atlas of African Lepidoptera. http://lepimap.adu.org.za.

Logan, J.A., Wollkind, D.J., Hoyt, S.C., Tanigoshi, L.K., 1976. An analytic model for description of temperature dependent rate phenomena in arthropods. Environ. Entomol. 5, 1133-1140.

Ma, G., Hoffmann, A.A., Ma, C.S., 2015. Daily temperature extremes play an important role in predicting thermal effects. J. Exp. Biol. 218, 2289-2296.

Maino, J.L., Kong, J.D., Hoffmann, A.A., Barton, M.G., Kearney, M.R., 2016. Mechanistic models for predicting insect responses to climate change. Curr. Opin. Insect Sci. 17, $81-86$.

Marshall, K.E., Sinclair, B.J., 2009. Repeated stress exposure results in a survival-reproduction trade-off in Drosophila melanogaster. Proc. R. Soc. B 277, 963-969.

Marshall, K.E., Sinclair, B.J., 2015. The relative importance of number, duration and intensity of cold stress events in determining survival and energetics of an overwintering insect. Funct. Ecol. 29, 357-366.

McLaughlin, B.C., Ackerly, D.D., Klos, P.Z., Natali, J., Dawson, T.E., Thompson, S.E., 2017. Hydrologic refugia, plants, and climate change. Glob. Change Biol. 23, 2941-2961.

Miquel, J., Lundgren, P.R., Bensch, K.G., Atlan, H., 1976. Effects of temperature on the life span, vitality and fine structure of Drosophila melangaster. Mech. Ageing Dev. 5, 347-370.

Mironidis, G., 2014. Development, survivorship and reproduction of Helicoverpa armigera (Lepidoptera: Noctuidae) under fluctuating temperatures. Bull. Entomol. Res. 104, $751-764$.

Mitchell, K.A., Boardman, L., Clusella-Trullas, S., Terblanche, J.S., 2017. Effects of nutrient and water restriction on thermal tolerance: a test of mechanisms and hypotheses. Comp. Biochem. Physiol. A 212, 15-23.

Morin, X., Thuiller, W., 2009. Comparing niche- and process-based models to reduce prediction uncertainty in species range shifts under climate change. Ecology 90, 1301-1313.

Müller, C., Cramer, W., Hare, W.L., Lotze-Campen, H., 2011. Climate change risks for African agriculture. Proc. Natl. Acad. Sci. U. S. A. 108, 4313-4315.

Nedvěd, A.D., Lavy, D., Verhoef, H.A., 1998. Modelling the time-temperature relationship in cold injury and effect of high-temperature interruptions on survival in a chill-sensitive collembolan. Funct. Ecol. 12, 816-824.

Nietschke, B.S., Magarey, R.D., Borchert, D.M., Calvin, D.D., Jones, E., 2007. A developmental database to support insect phenology models. Crop Prot. 26, 1444-1448.

Oostra, V., de Jong, M.A., Invergo, B.M., Kesbeke, F., Wende, F., Brakefield, P.M., Zwaan, B.J., 2011. Translating environmental gradients into discontinuous reaction norms via hormone signalling in a polyphenic butterfly. Proc. R. Soc. B 278, 789-797.

Parmesan, C., Ryrhom, N., Stefanescu, C., Hill, J., Thomas, C., Descimon, H., Huntley, B., Kaila, L., Kullberg, J., Tammaru, T., Tennent, W., Thomas, J., Warren, M., 1999. Poleward shifts in geographical ranges of butterfly species associated with regional warming. Nature 399, 579-583.

Phillips, S.J., Anderson, R.P., Schapire, R.E., 2006. Maximum entropy modeling of species geographic distributions. Ecol. Modell. 190, 231-259.

Pijpe, J., Brakefield, P.M., Zwaan, B.J., 2007. Phenotypic plasticity of starvation resistance in the butterfly Bicyclus anynana. Evol. Ecol. 21, 589-600.

Pincebourde, S., Woods, H.A., 2012. Climate uncertainty on leaf surfaces: the biophysics of leaf microclimates and their consequences for leaf-dwelling organisms. Funct. Ecol. 26, 844-853.

Pinheiro, J., Bates, D., DebRoy, S., Sarkar, D., R Core Team, 2018. Linear and Nonlinear Mixed Effects Models. For R Version 3.1-137. https://CRAN.R-project.org/package = nlme.

Potter, K.A., Woods, H.A., Pincebourde, S., 2013. Microclimatic challenges in global change biology. Glob. Change Biol. 19, 2932-2939.

R Core Team, 2014. R: A Language and Environment for Statistical Computing. R Foundation for Statistical Computing, Vienna, Austria. http://www.R-project.org/.

Renault, D., Nedvĕd, O., Hervant, F., Vernon, P., 2004. The importance of fluctuating thermal regimes for repairing chill injuries in the tropical beetle Alphitobius diaperinus (Coleoptera: Tenebrionidae) during exposure to low temperature. Physiol. Entomol. 29, 139-145.

Reside, A.E., VanDerWal, J.J., Kutt, A.S., Perkins, G.C., 2010. Weather, not climate, defines distributions of vagile bird species. PLoS One 5, e13569.
Riahi, K., Rao, S., Krey, V., et al., 2011. RCP 8.5 - a scenario of comparatively high greenhouse gas emissions. Clim. Change 109, 33-57.

Robin, X., Turck, N., Hainard, A., Tiberti, N., Lisacek, F., Sanchez, J.-C., Müller, M., 2011. pROC: an open-source package for R and S + to analyze and compare ROC curves. BMC Bioinf. 12, 77-84.

Rohmer, C., David, J.R., Moreteau, B., Joly, D., 2004. Heat induced male sterility in Drosophila melanogaster: adaptive genetic variations among geographic populations and role of the Y chromosome. J. Exp. Biol. 207, 2735-2743.

Sears, M.W., Raskin, E., Angilletta, M.J., 2011. The world is not flat: defining relevant thermal landscapes in the context of climate change. Integr. Comp. Biol. 51, 666-675.

Serdeczny, O., Adams, S., Baarsch, F., et al., 2016. Climate change impacts in SubSaharan Africa: from physical changes to their social repercussions. Reg. Environ. Change 6, 1585-1600.

Sgro, C.M., Terblanche, J.S., Hoffmann, A.A., 2016. What can plasticity contribute to insect responses to climate change? Ann. Rev. Entomol. 61, 433-451.

Sheldon, K.S., Dillon, M.E., 2016. Beyond the mean: biological impacts of cryptic temperature change. Integr. Comp. Biol. 56, 110-119.

Sinclair, B.J., Williams, C.M., Terblanche, J.S., 2012. Variation in thermal performance among insect populations. Physiol. Biochem. Zool. 85, 594-606.

Sinclair, B.J., Ferguson, L.V., Salehipour-shirazi, G., MacMillan, H.A., 2013. Cross-tolerance and Cross-talk in the cold: relating low temperatures to desiccation and immune stress in insects. Integr. Comp. Biol. 53, 545-556.

Sinclair, B.J., Coello Alvarado, L.E., Ferguson, L.V., 2015. An invitation to measure insect cold tolerance: methods, approaches, and workflow. J. Therm. Biol. 53, 180-197.

Sinclair, B.J., Marshall, K.E., Sewell, M.A., et al., 2016. Can we predict ectotherm responses to climate change using thermal performance curves and body temperatures? Ecol. Lett. 19, 1372-1385.

Swets, J.A., 1979. ROC analysis applied to the evaluation of medical imaging techniques. Invest. Radiol. 14, 109-121.

Tauber, M.J., Tauber, C.A., 1976. Insect diapause maintenance, termination, and postdiapause development. Annu. Rev. Entomol. 21, 81-107.

Taylor, K.E., Stouffer, R.J., Meehl, G.A., 2012. An Overview of CMIP5 and the experiment design. Bull. Am. Meteor. Soc. 93, 485-498.

Terblanche, J.S., Klok, C.J., Krafsur, E.S., Chown, S.L., 2006. Phenotypic plasticity and geographic variation in thermal tolerance and water loss of the Tsetse Glossina pallidipes (Diptera: Glossidae): Implications for distribution modelling. Am. J. Trop. Med. Hyg. 74, 786-794.

Terblanche, J.S., Deere, J.A., Clusella-Trullas, S., Janion, C., Chown, S.L., 2007. Critical thermal limits depend on methodological context. Proc. R. Soc. B 274, 2935-2943.

Terblanche, J.S., Hoffmann, A.A., Mitchell, K.A., Rako, L., le Roux, P.C., Chown, S.L., 2011. Ecologically relevant measures of tolerance to potentially lethal temperatures. J. Exp. Biol. 214, 3713-3725.

Tierney, J.E., Ummenhofer, C.C., de Menocal, P.B., 2015. Past and future rainfall in the Horn of Africa. Sci. Adv. 1, e1500682.

Todgham, A.E., Stillman, J.H., 2013. Physiological responses to shifts in multiple environmental stressors: relevance in a changing world. Integr. Comp. Biol. 53, 539-544.

Tonnang, H.E., Mohamed, S.F., Khamis, F., Ekesi, S., 2015. Identification and risk assessment for worldwide invasion and spread of Tuta absoluta with a focus on SubSaharan Africa: implications for phytosanitary measures and management. PLoS One $10, \mathrm{e} 0135283$.

Tonnang, Z.E.H., Hervc, B.D.B., Biber-Freudenberger, L., et al., 2017. Advances in crop insect modelling methods - towards a whole system approach. Ecol. Modell. 354, 88-103.

Usua, E.J., 1968. Temperature and relative humidity effects on the development of the immature stages of the maize stem borers Busseola fusea and Sesamia ealamistis. J. Econ. Entomol. 61, 1091-1093.

van den Heuvel, J., Saastamoinen, M., Brakefield, P.M., Kirkwood, T.B.L., Zwaan, B.J., Shanley, D.P., 2013. The predictive adaptive response: modeling the life-history evolution of the Butterfly Bicyclus anynana in seasonal environments. Am. Nat. 181, E28-E42.

VanDerWal, J., Murphy, H.T., Kutt, A.S., Perkins, G.C., Bateman, B.L., Perry, J.J., Reside, A.E., 2012. Focus on poleward shifts in species' distribution underestimates the fingerprint of climate change. Nat. Clim. Change 3, 239-243.

Way, M.J., 1995. Developmental biology of the immature stages of Eldana saccharina Walker (Lepidoptera: pyralidae). Proc. S. Afr. Sugar Technol. Assoc. 69, 38.

Wheeler, T., von Braun, J., 2013. Climate change impacts on global food security. Science $341,508-513$.

Wright, A.N., Schwartz, M.W., Hijmans, R.J., Shaffer, H.B., 2015. Advances in climate models from CMIP3 to CMIP5 do not change predictions of future habitat suitability for California reptiles and amphibians. Clim. Change 134, 579-591.

Zachariassen, K.E., 1985. Physiology of cold tolerance in insects. Physiol. Rev. 65, 799-832.

Zhou, Z.S., Rasmann, S., Li, M., Guo, J.Y., Chen, H.S., Wan, F.H., 2013. Cold temperatures increase cold hardiness in the next generation Ophraella communa Beetl. PLoS One 8, e74760. 